\title{
Effectiveness of therapeutic footwear for children: A systematic review
}

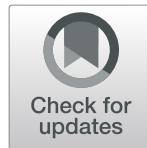

\author{
Matthew Hill ${ }^{*} \mathbb{D}$, Aoife Healy and Nachiappan Chockalingam
}

\begin{abstract}
Background: It is estimated that $2 \%$ of the global childhood population is living with some form of mobility impairment. Although footwear interventions are proposed to aid ambulation, there appears to be a paucity in the understanding of the effects of therapeutic footwear. This review aims to explore the effectiveness of footwear as an intervention for mobility impairment in children.

Methods: A systematic search of MEDLINE, CINAHL, PubMed, SPORTdiscus and Scopus databases were performed. Studies which focused on children with some form of mobility impairment, age of 9 months to 18 years, therapeutic footwear that allowed walking, and outcome measures that had explored biomechanical or skeletal geometry or psychosocial aspects were included in this review. Modified Downs and Black quality assessment index of randomised and non-randomised studies were used to assess the methodologies of included papers.

Results: Out of 5003 articles sourced, 13 met the inclusion criteria for this review. These were grouped into two titled "corrective and "functional" based on the types of footwear used for intervention. Studies within the corrective footwear group included participants aged 11 months to 5 years with moderate congenital talipes equino varus or mobile pes planus. While using skeletal geometry as an outcome, there was a limited fair quality (level II) evidence that corrective footwear has no significant effect on the development of pes planus but may assist in the reduction of deformity in congenital talipes equino varus. The functional footwear group included participants aged 3 to 17 years, predominantly with mobile pes planus or cerebral palsy. Based on biomechanical measures as an outcome, there was a limited fair quality (level III) evidence that functional footwear alters biomechanical parameters in mobile pes planus (spatiotemporal) and cerebral palsy (spatiotemporal, kinematic). Although psychosocial outcomes were considered within two studies, the analysis was limited.
\end{abstract}

Conclusion: Only a limited number of studies have explored the effects of therapeutic footwear and only in a narrow range of mobility impairments. Further high-quality research is required to improve the evidence base for the effectiveness of therapeutic footwear. This should include a wide range of mobility impairments and should focus both on physical and psychosocial outcomes.

Keywords: Shoes, Orthotic Devices, Disability, Child, Adolescent, Paediatric, Mobility Limitation, Assistive Devices

\footnotetext{
* Correspondence: matthew.hill@research.staffs.ac.uk

Centre for Biomechanics and Rehabilitation Technologies, Staffordshire

University, Stoke on Trent ST4 2DF, UK
} 


\section{Background}

Mobility impairment in children consists of a range of congenital or acquired conditions that may be neurological, musculoskeletal or combined in nature, representing a spectrum of moderate to severe disability [1]. Mobility impairment affects the body structure and function of a child which may lead to considerable social and health detriments [1-3]. Around $2 \%$ of the childhood population is estimated to be living with some form of mobility impairment [1-5] with a number of these conditions requiring supportive intervention to aid ambulation [6,7].

Footwear is used as an intervention to aid ambulation in mobility-impaired children [6-10]. Footwear intended for therapeutic purposes in children consists of a broad range of designs and clinical applications including pes planus, talipes equino varus, toe walking, cerebral palsy and developmental delay $[9,11-16]$. Footwear appears to be widely prescribed as an assistive device by some healthcare professionals [17], and a number of studies demonstrate that conventional footwear has significant effects on typically developing children's gait $[18,19]$. However, in contrast to other assistive aids such as ankle-foot orthoses which have seen an increase in research [20-23], there appears to be a lack of understanding on the design, effects and purpose of therapeutic footwear on children living with a mobility impairment [24-26].

A recent scoping review by the authors [24] highlighted that children's footwear research has shown a rapid increase in the past 10 years. However, footwear intended for therapeutic purposes was represented in just a small proportion of the recent literature, with limited empirical work and no focused review exploring its effects in comparison to that of conventional children's footwear. There was also no precise terminology to define therapeutic footwear and the specifics of its role in children living with mobility impairment. The scoping review suggested that the term children's therapeutic footwear be used as the standard definition for footwear that is designed specifically with the purpose to support or alleviate mobility impairment in childhood. Further to this, subgroupings of therapeutic footwear were suggested dependent on the intended therapeutic role: Corrective (footwear designed to bring about the correction of congenital skeletal lower limb alignment); Accommodative (footwear designed to reduce compression and shearing stresses on children's foot deformities through the dimensional matching of footwear to the child's foot); and Functional (footwear designed to improve dynamic gait parameters of children with mobility impairment). In addition, the scoping review highlighted the need for a systematic assessment of the level and quality of evidence of children's therapeutic footwear research.
The overall aim of the systematic review is to establish the effectiveness of therapeutic footwear in the treatment of mobility impairment in children.

The objectives are to:

1. systematically search the published literature to identify studies that have explored the physical or psychosocial effects of therapeutic footwear on children with mobility impairment.

2. establish the levels of evidence and quality of evidence of the available research literature concerning children's therapeutic footwear.

3. explore the benefits and/or adverse effects of therapeutic footwear interventions.

\section{Methodology}

The systematic review followed the PRISMA guidelines [27]. Consideration was also given to recommendations for conducting systematic reviews on paediatric participants $[28,29]$. The protocol for the review was registered with PROSPERO: International prospective register of systematic reviews (CRD42018097038) [30].

\section{Searches}

A search strategy using medical subject headings (MeSH) and free-text terms related to children and footwear were developed. Databases used in this search were MEDLINE, PubMed, CINAHL, SCOPUS, and Sportdiscus. An example of the search strategy can be found in Additional file 1 . The search strategy was adapted across the databases to capture eligible articles published from database inception to February $1^{\text {st }}, 2018$.

\section{Eligibility of studies}

Study designs considered for this review included randomised control trials (RCTs), non-randomised controlled trials, experimental before-after studies, prospective and retrospective comparative cohort studies, and casecontrol studies. Case series and case report studies were not considered for inclusion. All articles to be available in full English language text.

Participants in the included studies were infants, children and adolescents of typical walking and shod age (9 months to 18 years of age) with some form of mobility impairment (defined as a musculoskeletal or neurological condition that affects motor performance). Individuals must be able to ambulate independently or with an assistive device (e.g., arm or underarm crutches, walking frames).

Interventions included the provision of therapeutic footwear to children with a mobility impairment that facilitates and allows ambulation. Studies were included where therapeutic footwear was provided and assessed separately as an independent variable. 
Therapeutic footwear that did not permit ambulation during wear (e.g., nocturnal braced footwear) were excluded. Comparators included studies that compare therapeutic footwear to barefoot, standard retail footwear, orthotic interventions and different types of therapeutic footwear.

Primary outcomes considered biomechanical and skeletal geometric measures assessing the effects of therapeutic footwear on lower limb development and function. Secondary outcomes considered measures assessing the effect of therapeutic footwear on children's quality of life, including, physical activity, societal participation, self-esteem, and pain. Reports of adverse effects (e.g. footwear fit related pain/discomfort) in the included studies were also considered.

\section{Study selection}

Prior to screening, all duplicates were removed using referencing software (Mendeley, Elsevier BV) and supplemented by a manual check by one reviewer $(\mathrm{MH})$. Screening followed on from the previous scoping review [24], where one reviewer ( $\mathrm{MH})$ had independently identified studies that considered children's footwear from a therapeutic perspective amongst the total records sourced. These abstracts were then screened by two reviewers $(\mathrm{MH}, \mathrm{AH})$ against the eligibility criteria of the systematic review with any uncertainty resolved through discussion with the third reviewer (NC). Full texts were located for all studies that appeared to meet the inclusion criteria and those studies where there was uncertainty regarding eligibility.

Two reviewers ( $\mathrm{MH}$ and $\mathrm{AH})$ independently screened the full-text articles to assess whether these met the eligibility criteria. Any disagreements regarding study eligibility between the reviewers were resolved through mediation with a third reviewer (NC).

\section{Data extraction}

A data extraction form was developed, and information relevant to the review question was extracted from the included studies [31]. These included author names, date of publication, study design, participant characteristics (number of participants, age, sex, height, mass), description of intervention and comparison, experimental methodology, duration of follow-up, primary and secondary outcomes, adverse events and key results. Data were extracted by one reviewer $(\mathrm{MH})$. The extracted data were checked for correctness and completeness against the full-text articles by a second reviewer (AH).

\section{Levels of evidence and quality assessment}

The levels of evidence of each included study were assessed by two reviewers ( $\mathrm{MH}$ and $\mathrm{AH}$ ) using the Oxford Centre for Evidence-Based Medicine level of evidence version 2 (OCEBM) [32]. The quality of the studies was assessed independently by two reviewers ( $\mathrm{MH}$ and $\mathrm{AH}$ ). Quality assessment was completed using the modified Downs and Black quality assessment index (QI) of randomised and non-randomised studies [33, 34], which has been used in previous systematic reviews of footwear and orthoses [18, 35]. Questions that were not applicable to the study under assessment were not applied (i.e. non-longitudinal studies, studies with only one testing group). Scores were therefore adjusted to an overall percentage to mitigate for the differing total scores. In line with Trac et al. (2016) [34] the percentage scores were grouped into the following four QI levels: excellent (92 to 100\%), good (71 to $91 \%$ ), fair (50 to $70 \%$ ), and poor (less than 50\%). Survey studies were assessed separately using the tool suggested by Burns and Kho [36]; this was carried out independently by two reviewers $(\mathrm{MH}$ and $\mathrm{AH})$.

Outcome measures from individual trials with acceptable levels of homogeneity in participant characteristics and experimental protocols were planned to be combined through meta-analysis. Where a meta-analysis was not possible, the results from clinically comparable trials were synthesised qualitatively. Data was grouped primarily on therapeutic footwear classification established in the previous scoping review [24], with subgrouping of the included studies dependent on the type of outcomes measures (biomechanical, skeletal geometry, quality of life), and pathology/medical condition.

\section{Results}

Database searches yielded 5003 unique articles (Fig. 1) with 3 further papers found through screening the reference lists of related reviews sourced from the previous scoping review [24]. From these, 80 articles were identified as discussing children's therapeutic footwear with 23 articles identified for full-text eligibility screening. Thirteen studies met the eligibility criteria for inclusion. A summary of the findings is presented in Tables 1, 2, 3, 4, 5 with supplementary results found in Additional files 2 and 3. Details of the levels of evidence and quality assessment of the included studies are provided in Additional files 4 and 5. None of the studies offered an acceptable level of homogeneity to allow the data to be combined for meta-analysis. This was due to a number of factors including, lack of sufficient detail to assure similar footwear design between studies, and incomplete description of the participants' characteristics (Table 1 and 2). These issues precluded a combined analysis even for those studies with the same footwear grouping, clinical condition and outcomes [12, 37]; therefore, only a qualitative analysis of the included studies was possible.

Analysis and synthesis of the studies were performed according to the grouping/subgrouping of footwear 


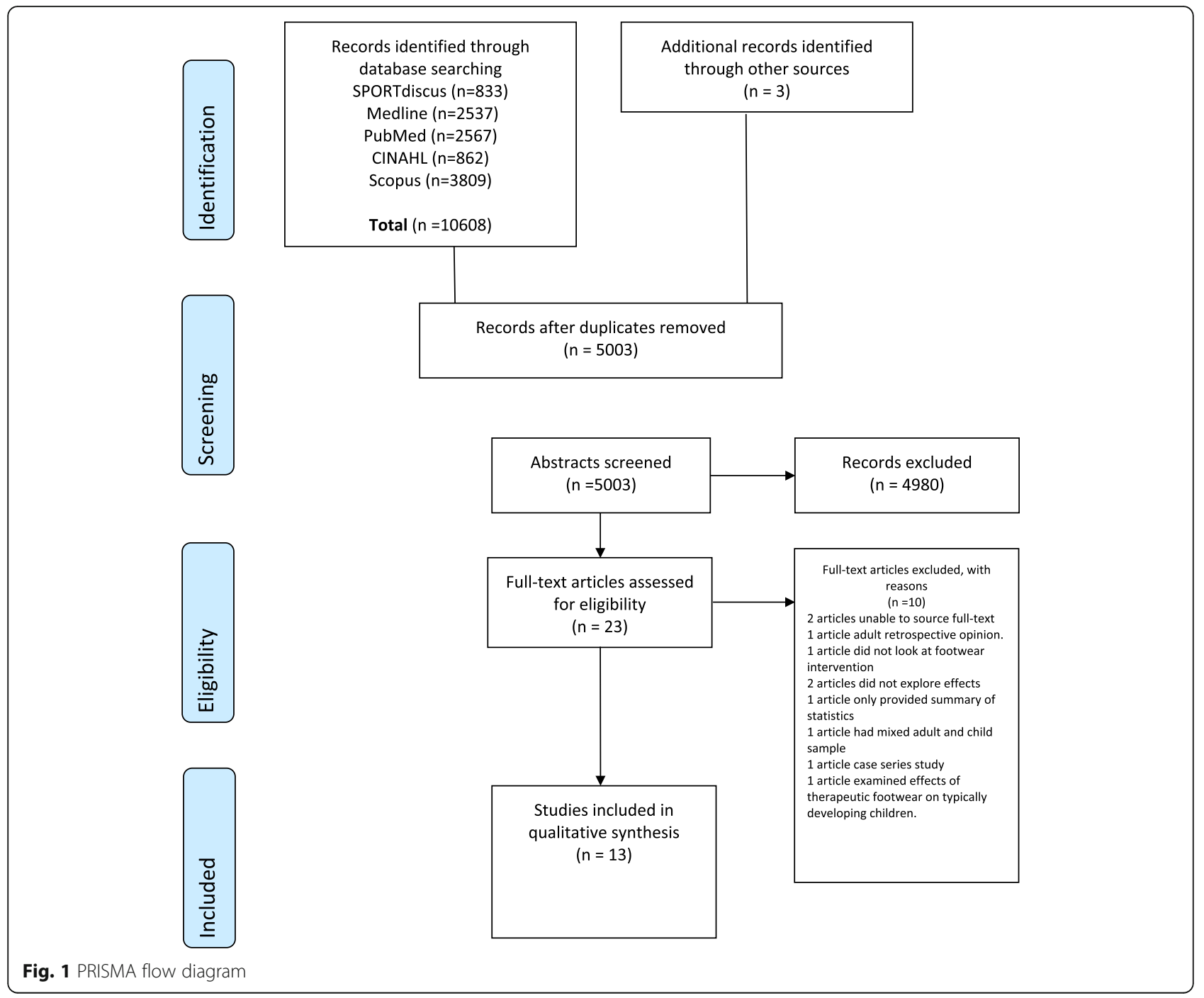

interventions, with further subdivision by the medical condition of the study participants (see Table 1 ).

\section{Therapeutic footwear interventions}

The types of therapeutic footwear interventions that were explored in the 13 studies fell into 2 of the previously defined groupings from the scoping review [24] corrective $(n=3)$ and functional $(n=10)$ (Table 1). No studies explored the effects of accommodative therapeutic footwear for children. None of the included studies reported adverse events or stated if such events were considered within the study plan.

\section{Corrective Footwear}

These three studies focused on the effects of the footwear on lower limb alignment pes planus $(n=2)[12,37]$ and congenital talipes equino varus (CTEV) $(n=1)[16]$ (Table 1). The studies were all randomised controlled trials (level II evidence). Two of the studies were of fair
QI [16, 37] and one of poor QI [12]. A total of 196 children were examined across the studies with an age range from 11 months to 5 years (Table 1, Additional file 2). One study failed to report the sex distribution amongst the experimental groups [12], and the height and mass of the participants were only reported in one study [16]. Two of the studies $[16,37]$ had sufficient sample size to detect a medium effect size of 0.3 at 0.05 significance and $80 \%$ power [45]. However, one of the studies suffered a loss to follow up $>20 \%$ [37] with no intention to treat factored into the analysis.

Various design characteristics were reported for the corrective footwear (Table 2) in the three studies. Consistent features appeared to be some form of reinforced or lengthened heel counter or arch inlay [12, 16, 37]. The common comparator to corrective footwear interventions across all three studies was daily wear of standard retail footwear (see Table 1). One study also considered orthotic arch support or heel cups [37]. 


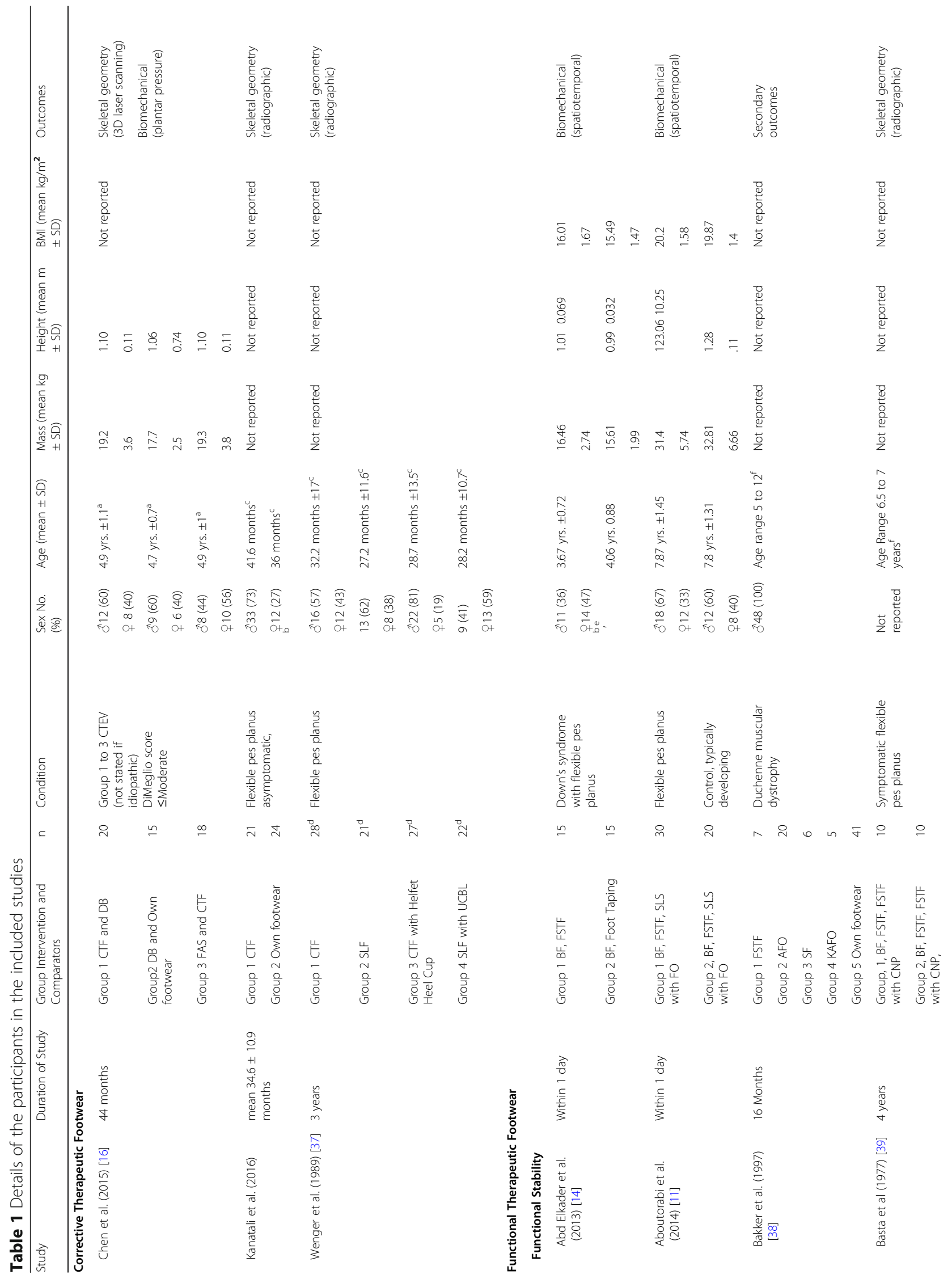




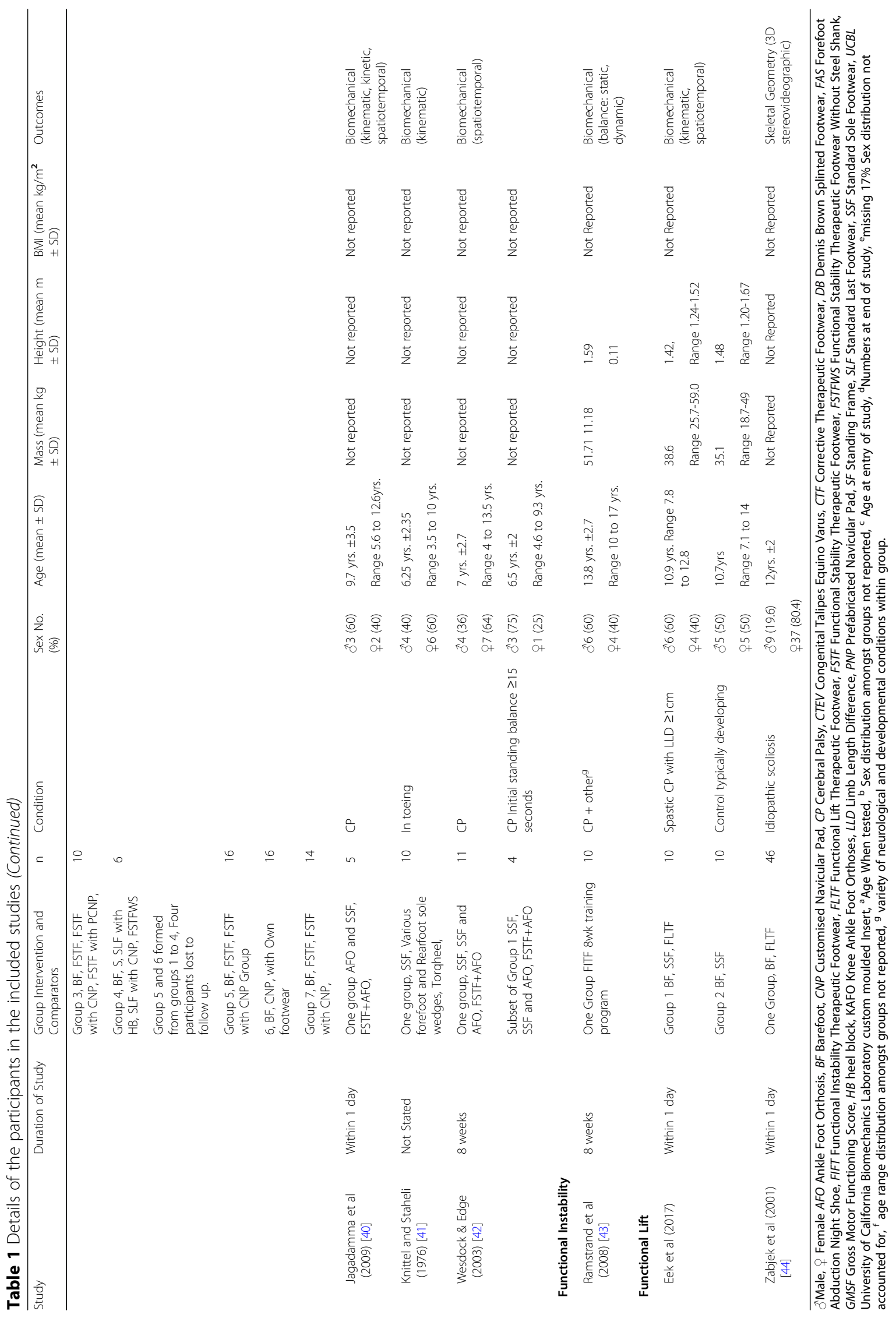


Table 2 Description of footwear interventions in included studies.

\begin{tabular}{|c|c|}
\hline Study & Description provided of therapeutic footwear intervention (s) \\
\hline \multicolumn{2}{|l|}{ Corrective Therapeutic Footwear } \\
\hline Chen et al (2015) [16] & Orthopaedic shoe with an orthopaedic insole and hard heel cup (CTF) \\
\hline Kanatli et al (2016) [12] & Custom made orthopaedic shoe, $0.5-0.9 \mathrm{~cm}$ longitudinal arch support, $3-4 \mathrm{~mm}$ heel wedges. (CTF) \\
\hline Wenger et al (1989) [37] & Orthopaedic shoe, steel shank, Thomas heel, long medial heel counter, navicular pad (CTF) \\
\hline \multicolumn{2}{|l|}{ Functional Therapeutic Footwear } \\
\hline \multicolumn{2}{|l|}{ Functional Stability } \\
\hline Abd Elkader et al (2013) [14] & Medical shoes same brand and model (brand/model not stated) with prefabricated arch insert (FSTF) \\
\hline Aboutorabi et al (2014) [11] & Custom made, High-top shoes, wide toe box, internal heel counter, arch inlay (FSTF) \\
\hline Bakker et al (1997) [38] & No details other than off the shelf orthopaedic footwear (FSTF) \\
\hline Basta et al (1977) [39] & High topped, Steel Shank, firm counter (FSTF) \\
\hline Jagadamma et al (2009) [40] & $\begin{array}{l}\text { Custom made heel to forefoot wedged EVA sole adhesion, used alongside AFO. Wedges adjusted } \\
\text { until shank to vertical angle reached } 12^{\circ} \text {. (FSTF+AFO) }\end{array}$ \\
\hline Knittel and Staheli (1976) [41] & $\begin{array}{l}\text { Low cut shoe with } 9 \text { various sole modifications, medial forefoot wedge only (FSTF 1), lateral forefoot } \\
\text { wedge only (FSTF 2), medial forefoot and medial rearfoot wedge } \\
\text { (FSTF 3), lateral forefoot and medial rearfoot wedge (FSTF 4), lateral forefoot and lateral rearfoot wedge } \\
\text { (FSTF 5), medial rearfoot wedge only (FSTF 6), lateral rearfoot wedge only (FSTF 7), parallel torqheel } \\
\text { (FSTF 8), circular torqheel (FSTF 9). }\end{array}$ \\
\hline Wesdock \& Edge (2003) [42] & $\begin{array}{l}\text { Custom made Styrofoam wedged sole adhesion, wedge = vertical distance of posterior inferior elevated } \\
\text { heel of the unaltered shoe from the floor when subject with crouch gait stood as erect as possible. (FSTF+AFO) }\end{array}$ \\
\hline \multicolumn{2}{|l|}{ Functional Instability } \\
\hline Ramstrand et al (2008) [43] & Masai Barefoot Technologies, MBT unstable sole shoe. (FITF) \\
\hline \multicolumn{2}{|l|}{ Functional Lift } \\
\hline Eek et al (2017) [10] & 12 mm EVA sole adhesion divided into two parts heel and forefoot, (FLTF) \\
\hline Zabjek et al (2001) [44] & Various sole lift adhesion $5 \mathrm{~mm}, 10 \mathrm{~mm}, 15 \mathrm{~mm}$, (FLTF) \\
\hline
\end{tabular}

AFO Ankle Foot Orthosis, CTF Correctional therapeutic footwear, FSTF Functional stability therapeutic footwear, FITF Functional instability therapeutic footwear, FLTF Functional lift therapeutic footwear

Assessors were blinded in only one of the three studies [37]. Primary outcomes focused on skeletal geometric measures which were presented in the three studies included in this grouping (Table 3). These were radiographic measures of the skeletal alignment of the foot in two studies considering pes planus [12,37], and 3D scanned images of the foot and ankle for the study considering CTEV [16]. Only one study in this grouping [16] considered biomechanical outcomes (Table 4) consisting of pressure ratios of the heel to forefoot and heel to lateral midfoot in walking conditions. Secondary outcomes, as determined by this current review, were not reported in any study amongst the corrective footwear grouping. Results indicated that there was no statistically significant effect of corrective footwear versus readily available retail footwear in the developmental of asymptomatic paediatric pes planus. Daily wear of corrective footwear in combination with nocturnal wear of Dennis Brown splint did not appear to offer any difference to the 3D scans of the trans-malleolar axis, and the bean-shaped ratio of CTEV in comparison to daily wear of standard footwear and nocturnal wear of Dennis Brown splint [16]. However, the study did demonstrate statistically significant improvements in 4 of the 13 plantar pressure measures (Table 4) indicating a reduction of equinus and varus deformity with the daily wear of corrective footwear and nocturnal use of Dennis Brown splint. Results for the nine plantar pressure measures that were not statistically significant concerning CTEV and corrective footwear, but highlighted the effects of different nocturnal splints, can be found in Additional file 3.

\section{Functional Footwear}

Functional footwear intervention studies focused chiefly on biomechanical primary outcomes (kinematic, kinetic, spatiotemporal, balance) (Table 4, Additional file 3) which were considered in 7 of the 10 studies [10,11, 14, 40-43]. Skeletal geometry primary outcomes (Table 3 ) were considered in only two of the studies [39, 44]. Secondary outcomes were considered in two studies [38, 39] but empirically reported in one [38] (Table 5). A total of 311 children were considered amongst the studies with an age range from 3 to 17 years (Table 1, Additional file 2). Reporting of the participants' height and mass was provided in four studies [10, 11, 14, 43] (Table 1). It was noted that the small sample size affected the statistical power in all but two of the experimental studies amongst 


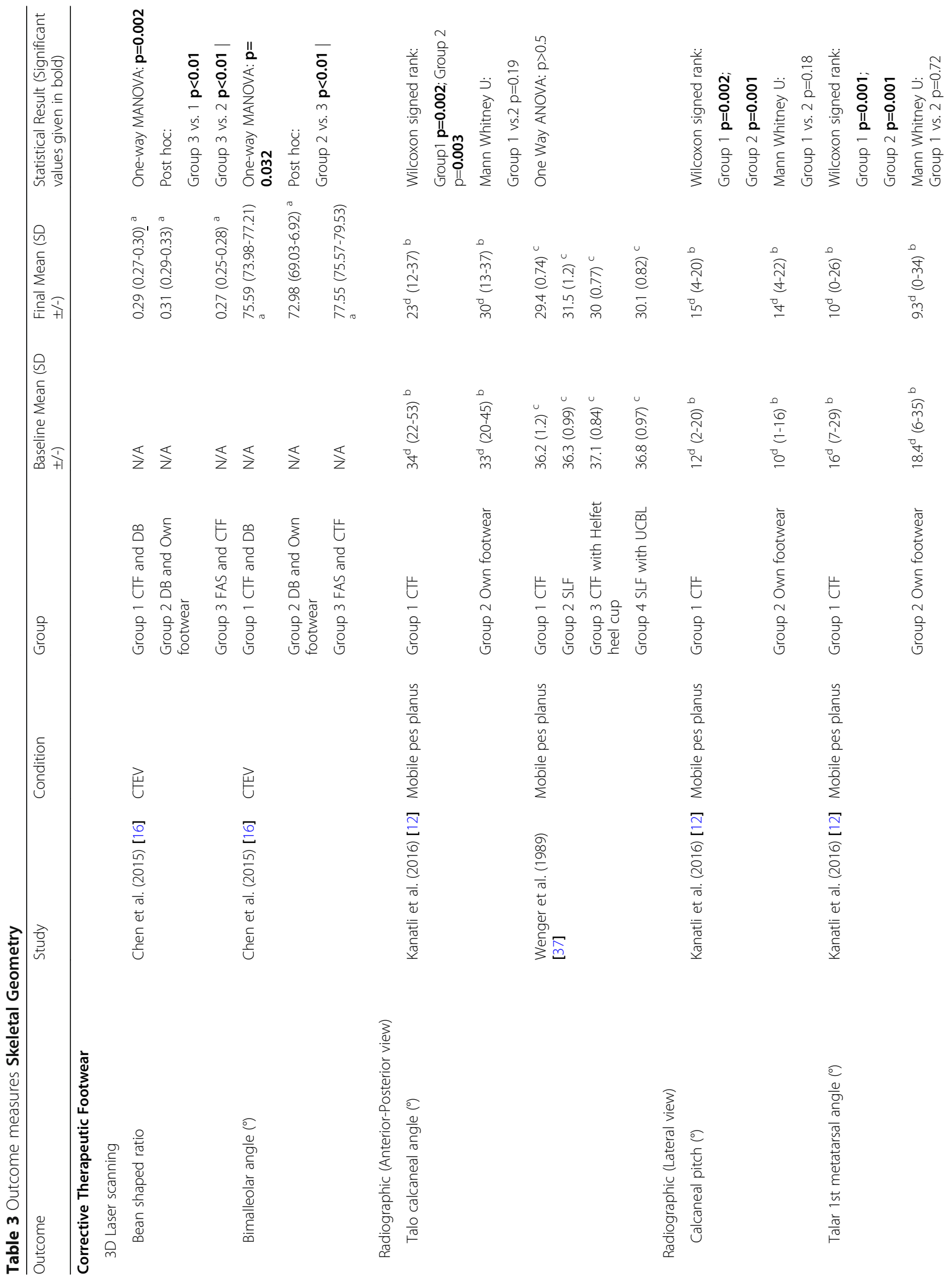




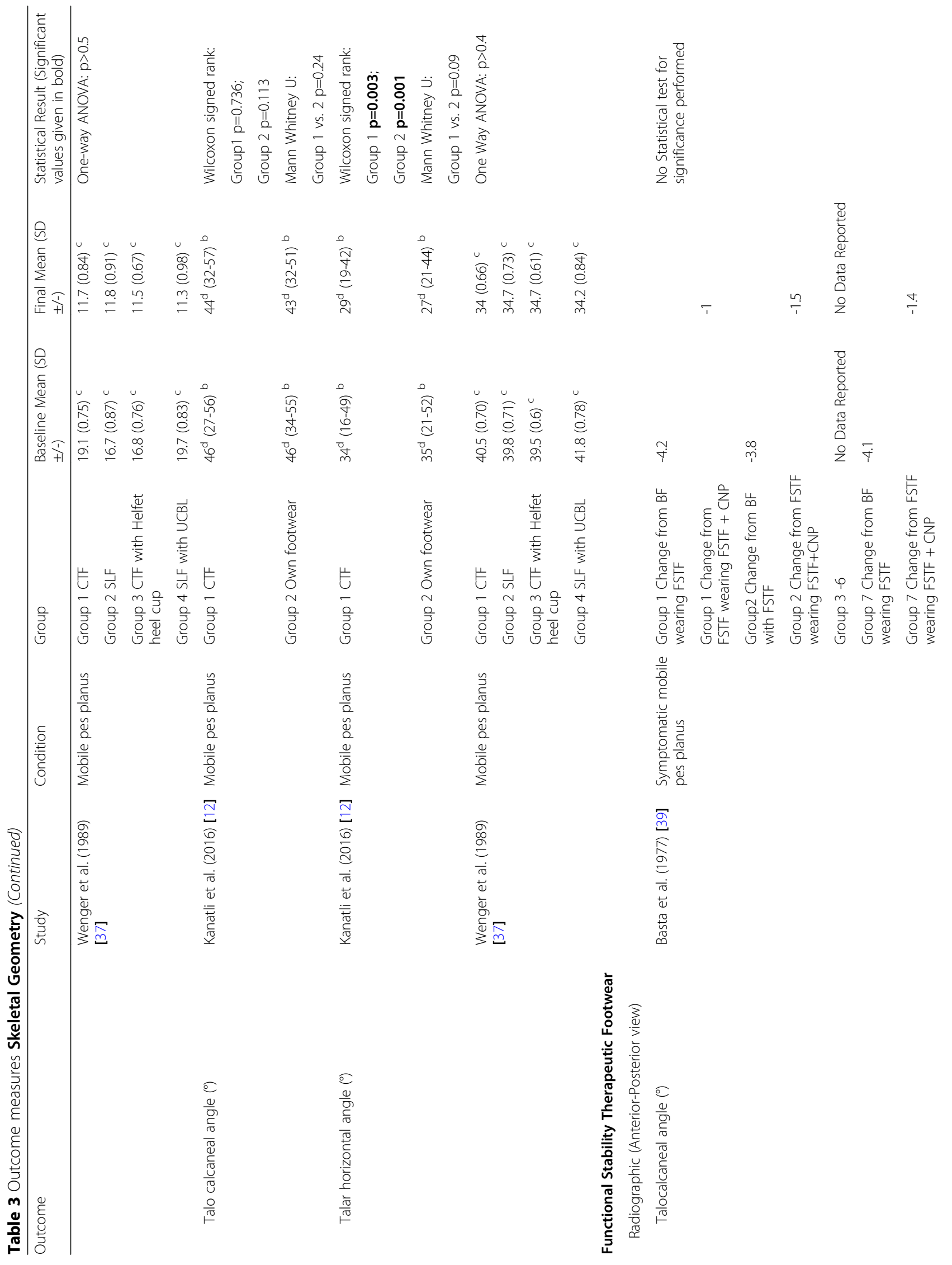




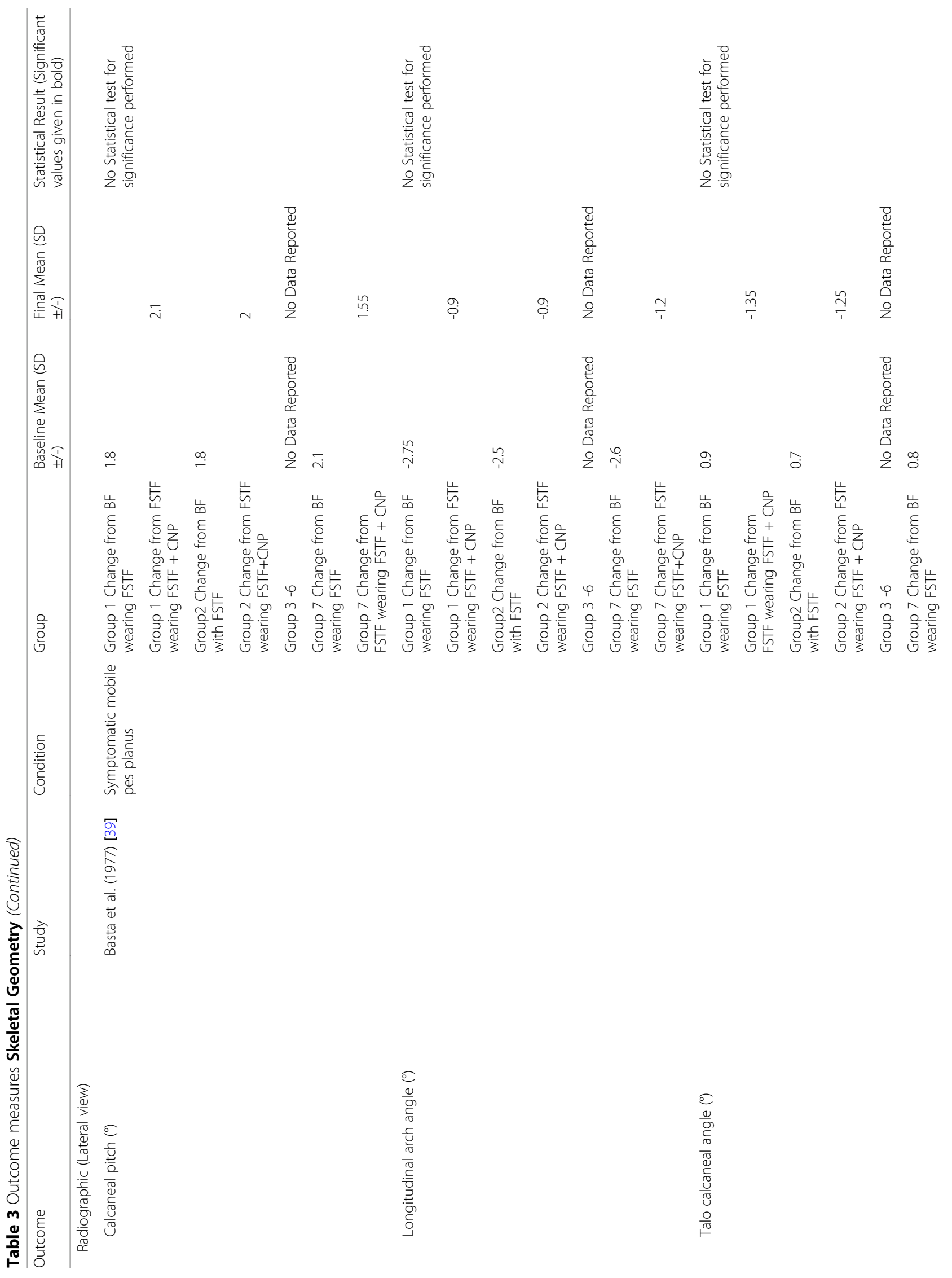




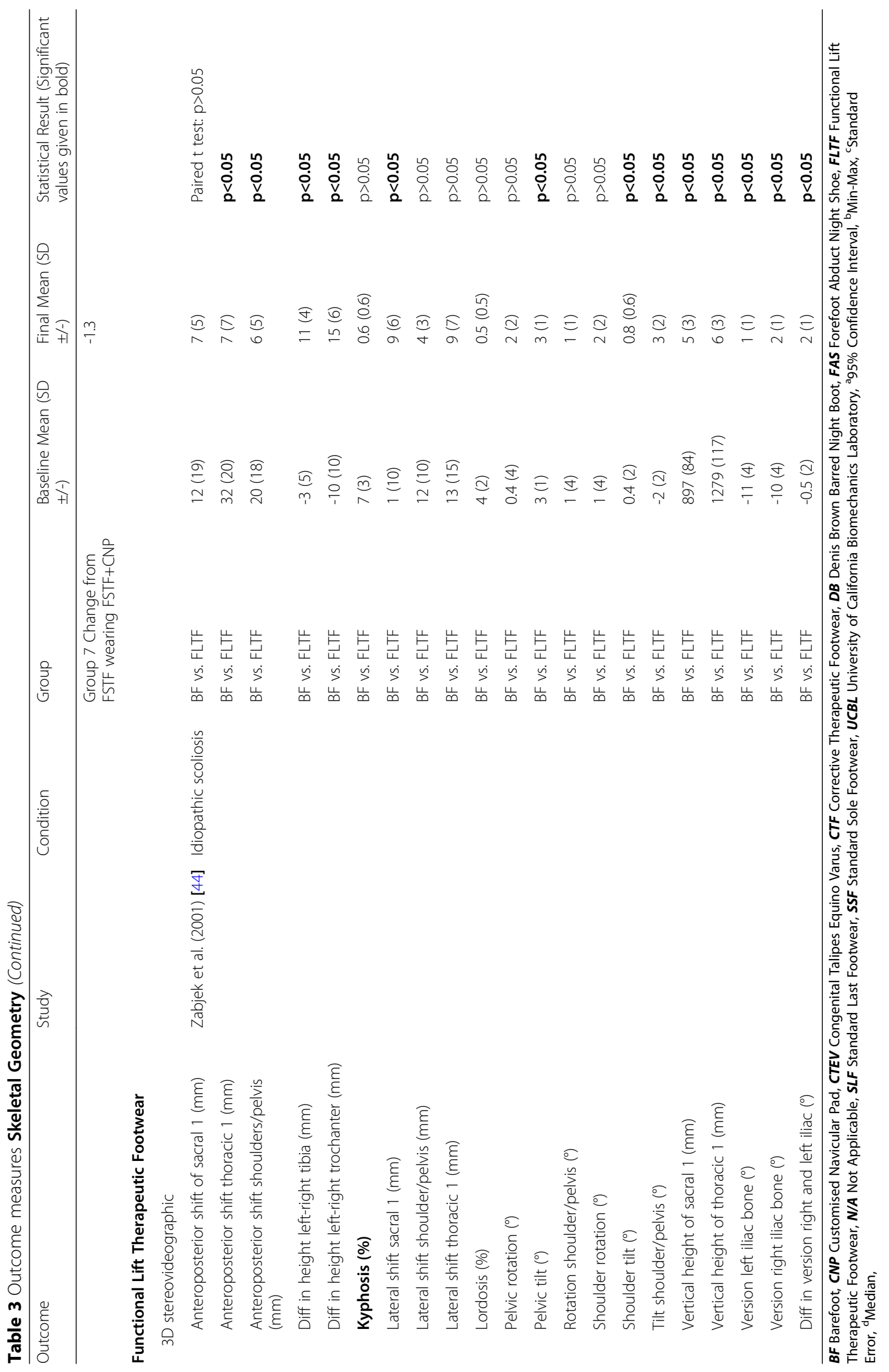


Hill et al. Journal of Foot and Ankle Research $\quad$ (2020) 13:23

Page 12 of 26

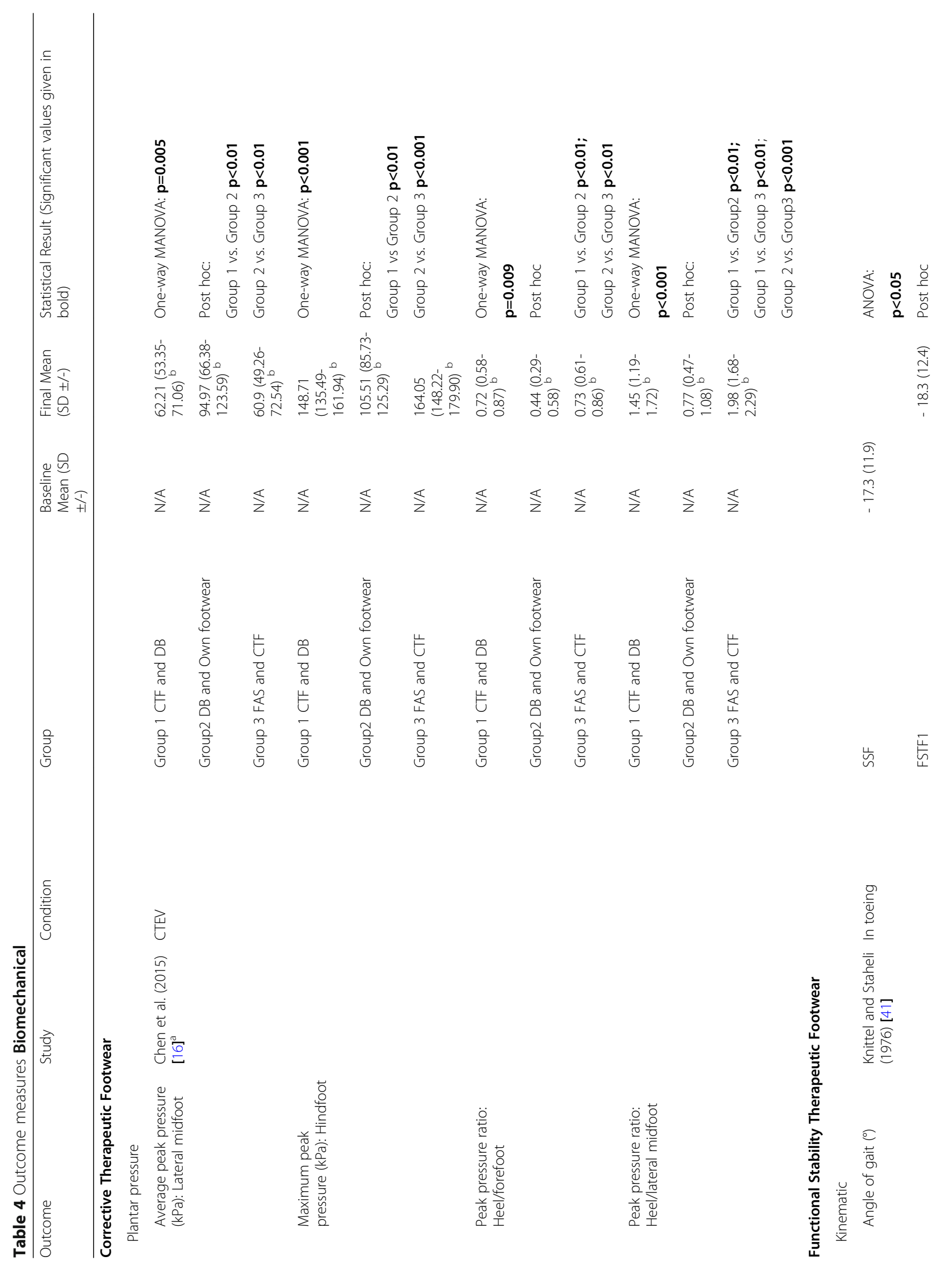




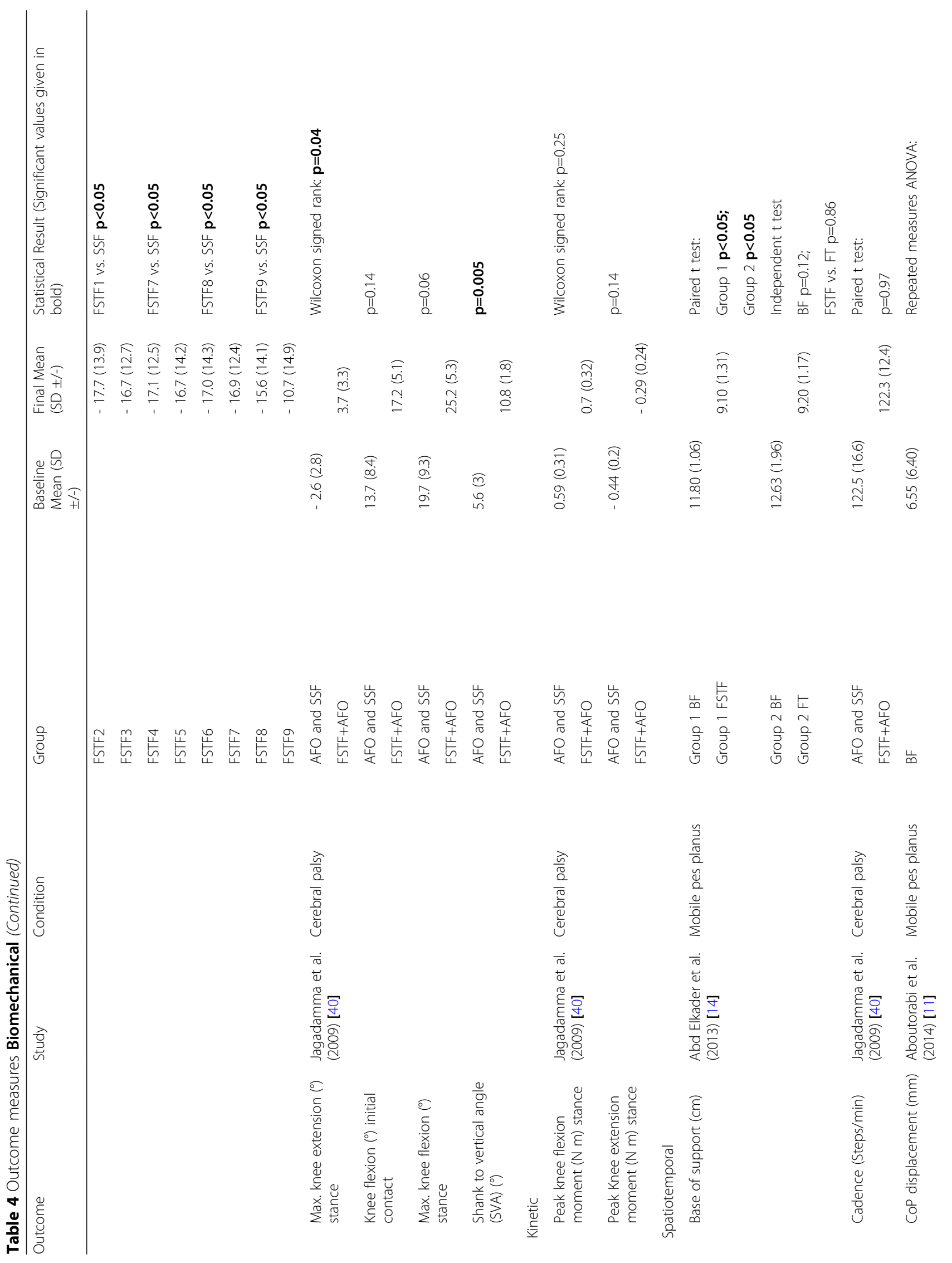




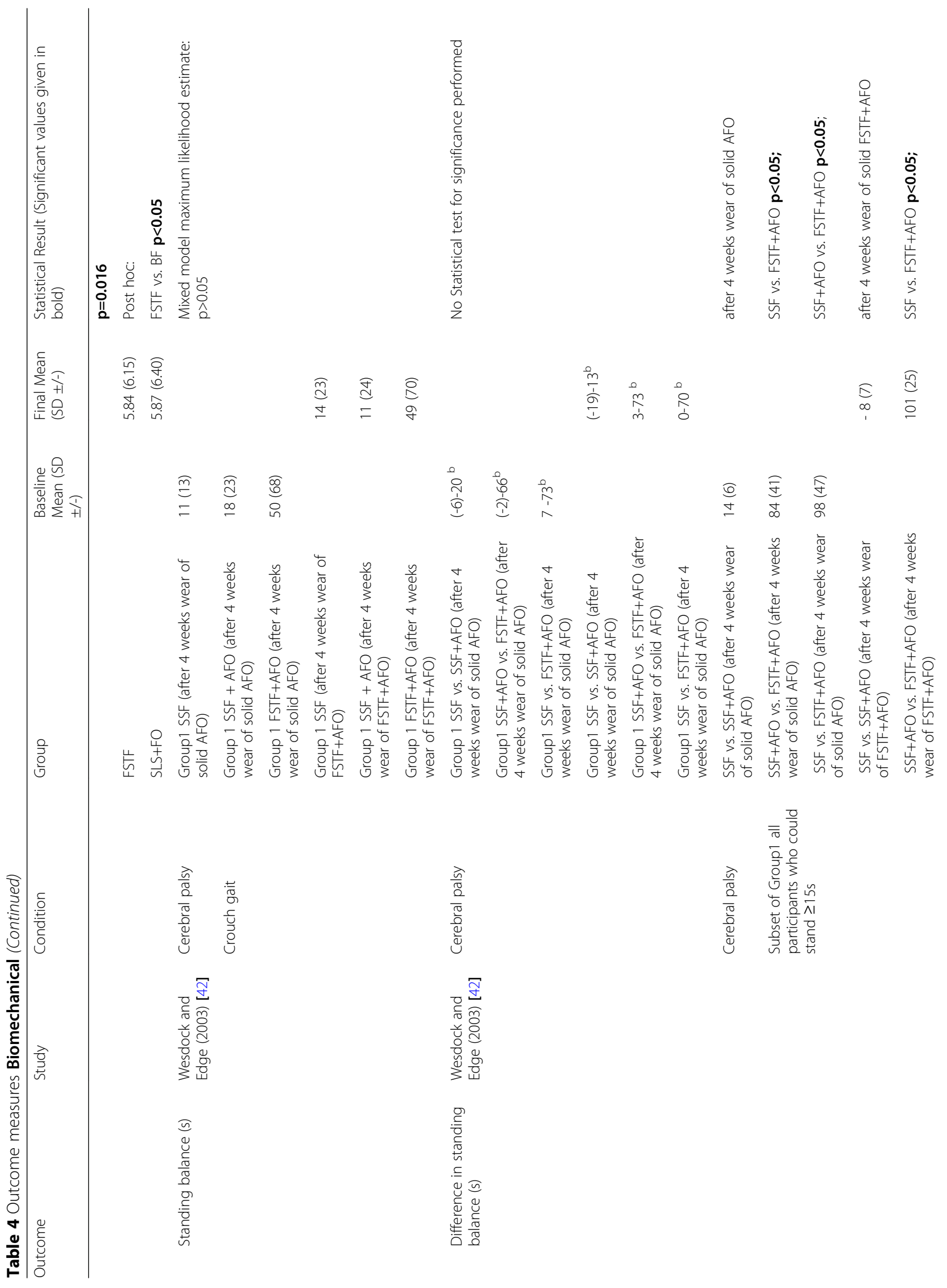




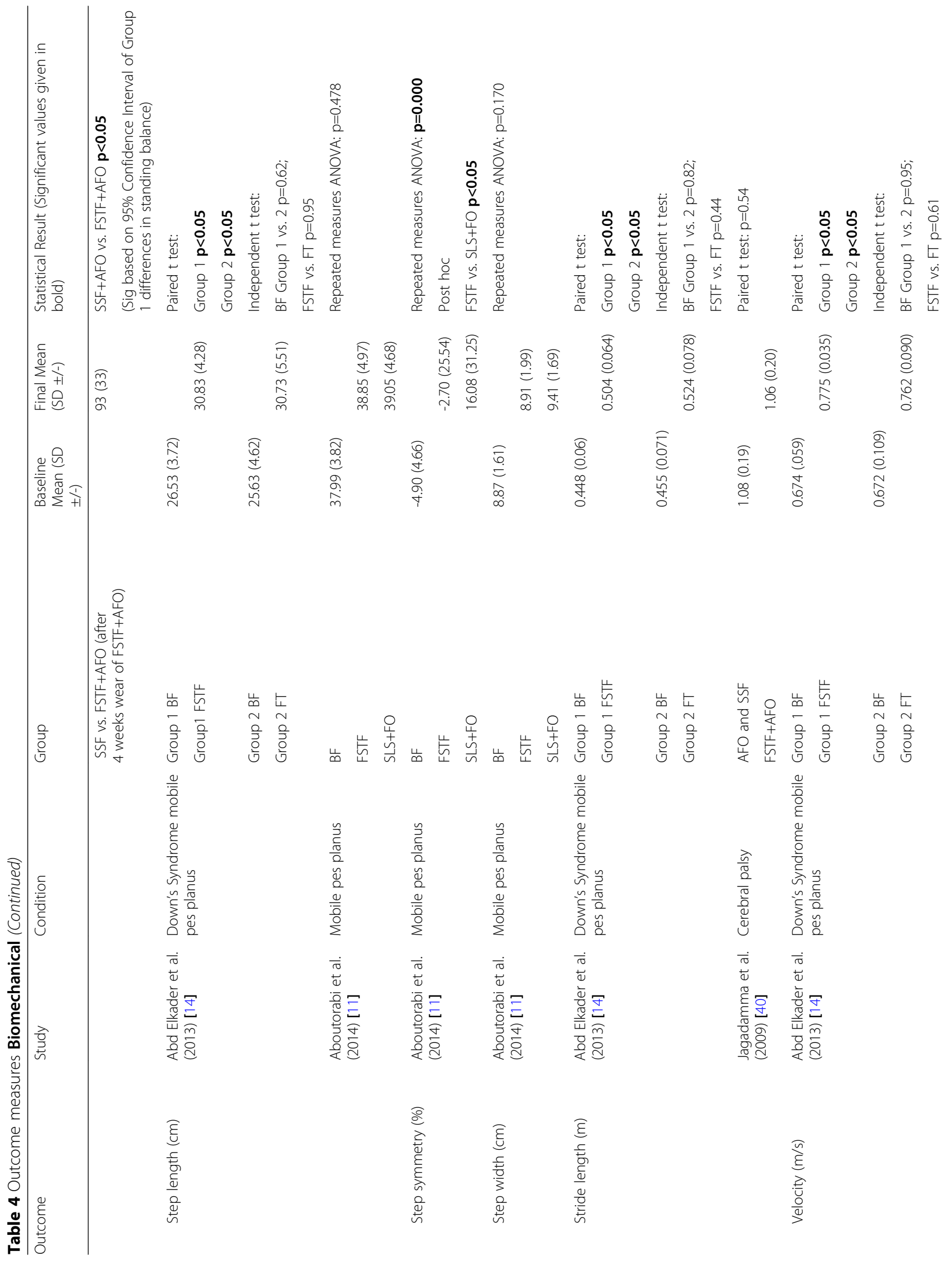




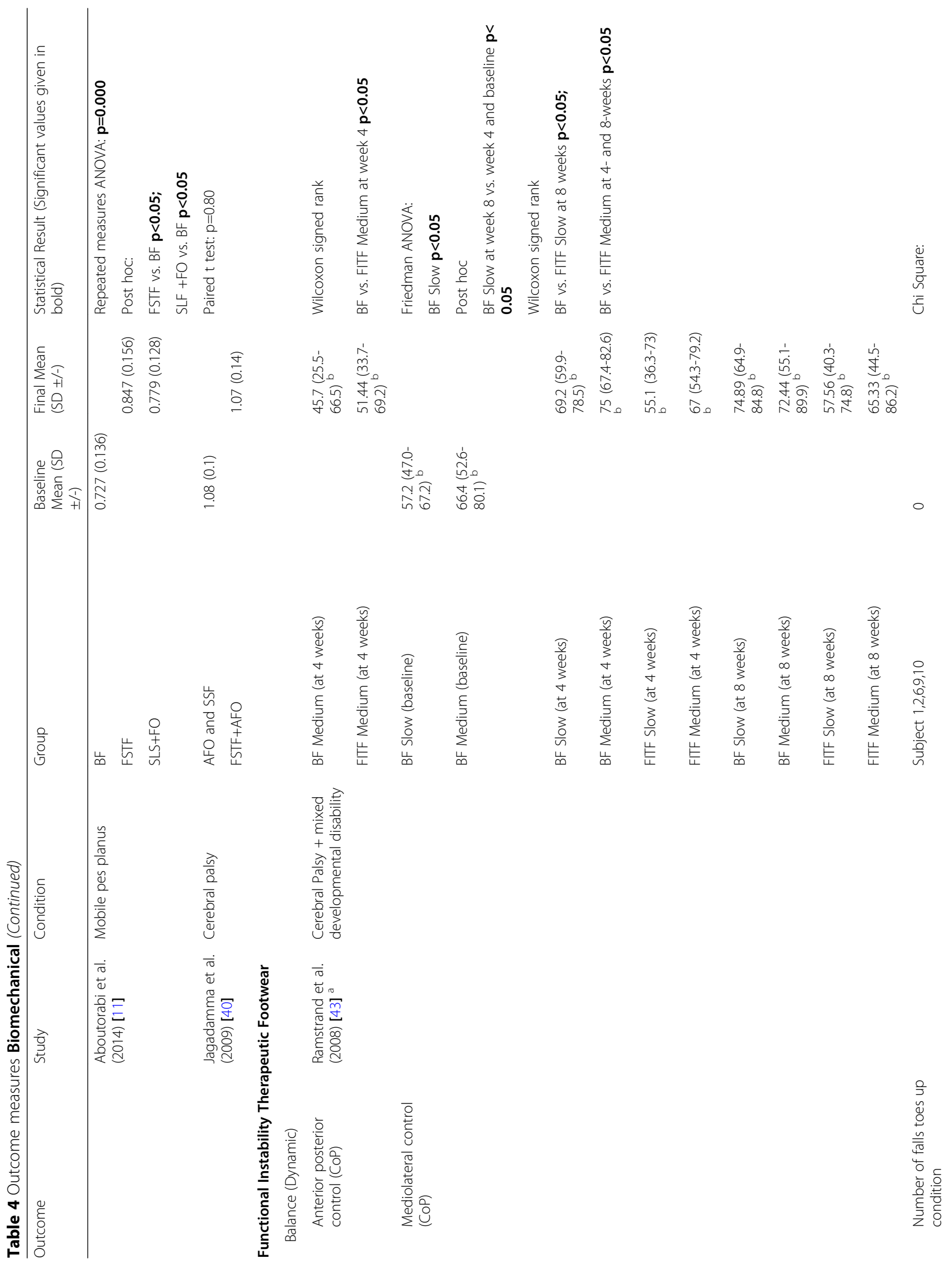




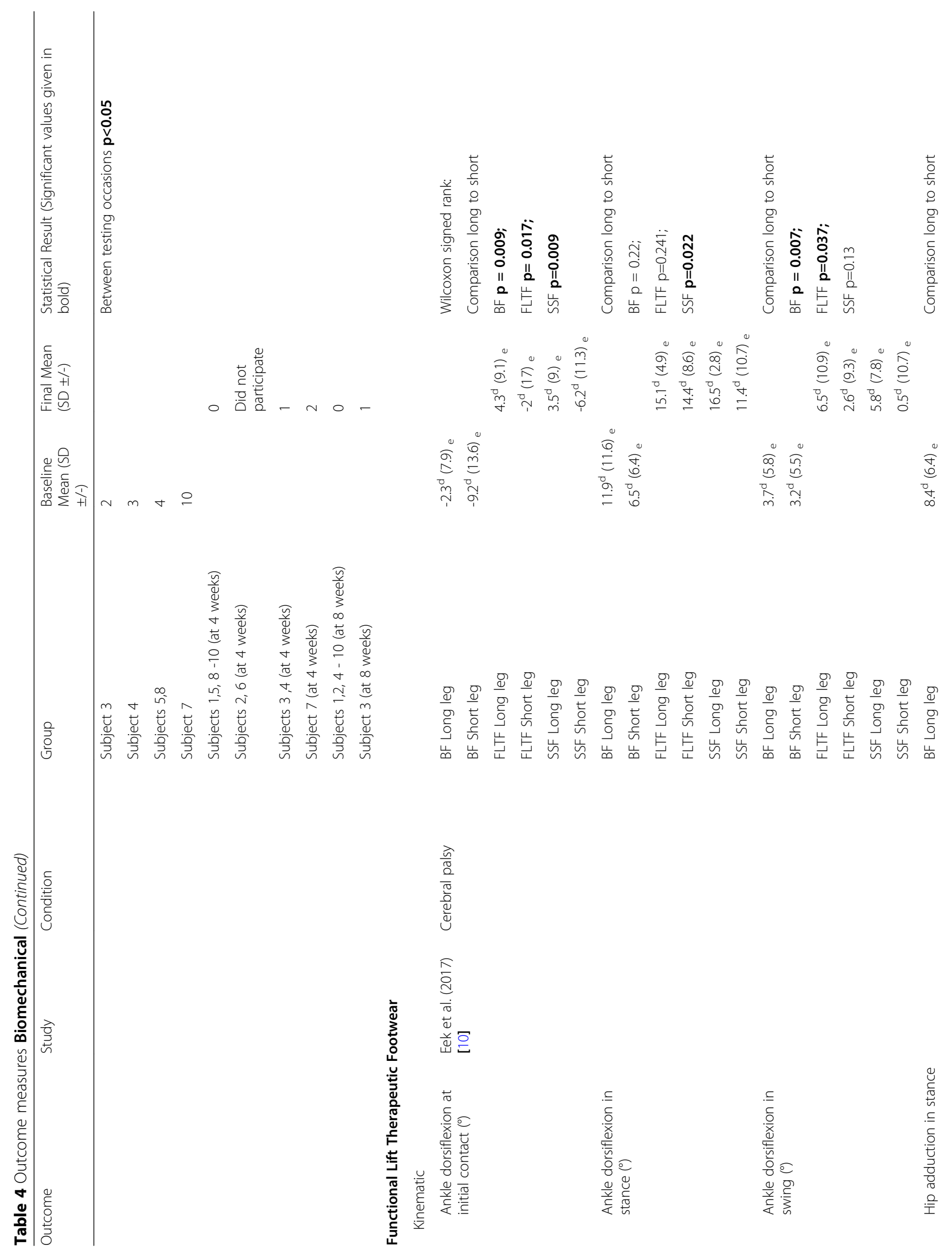




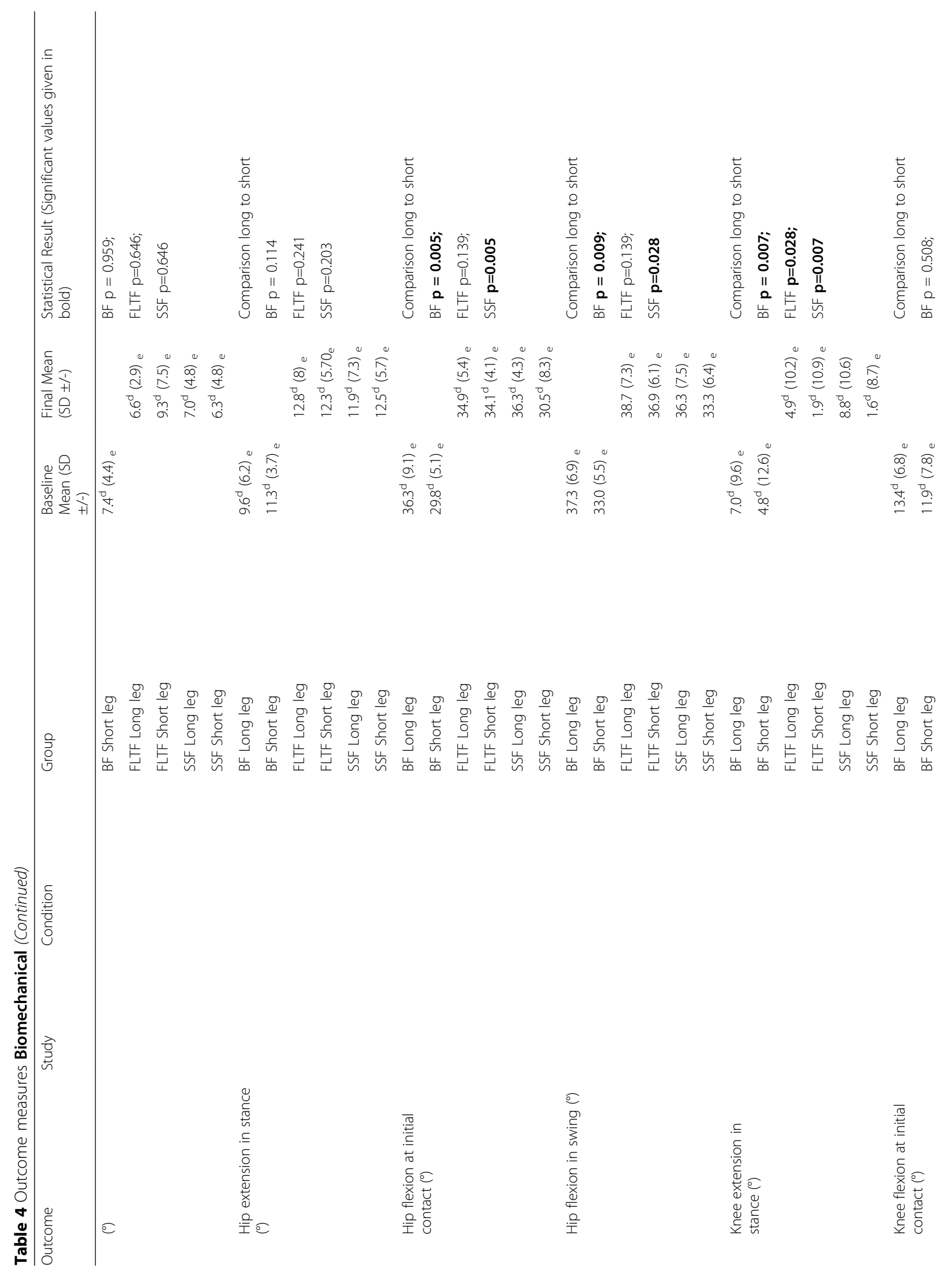




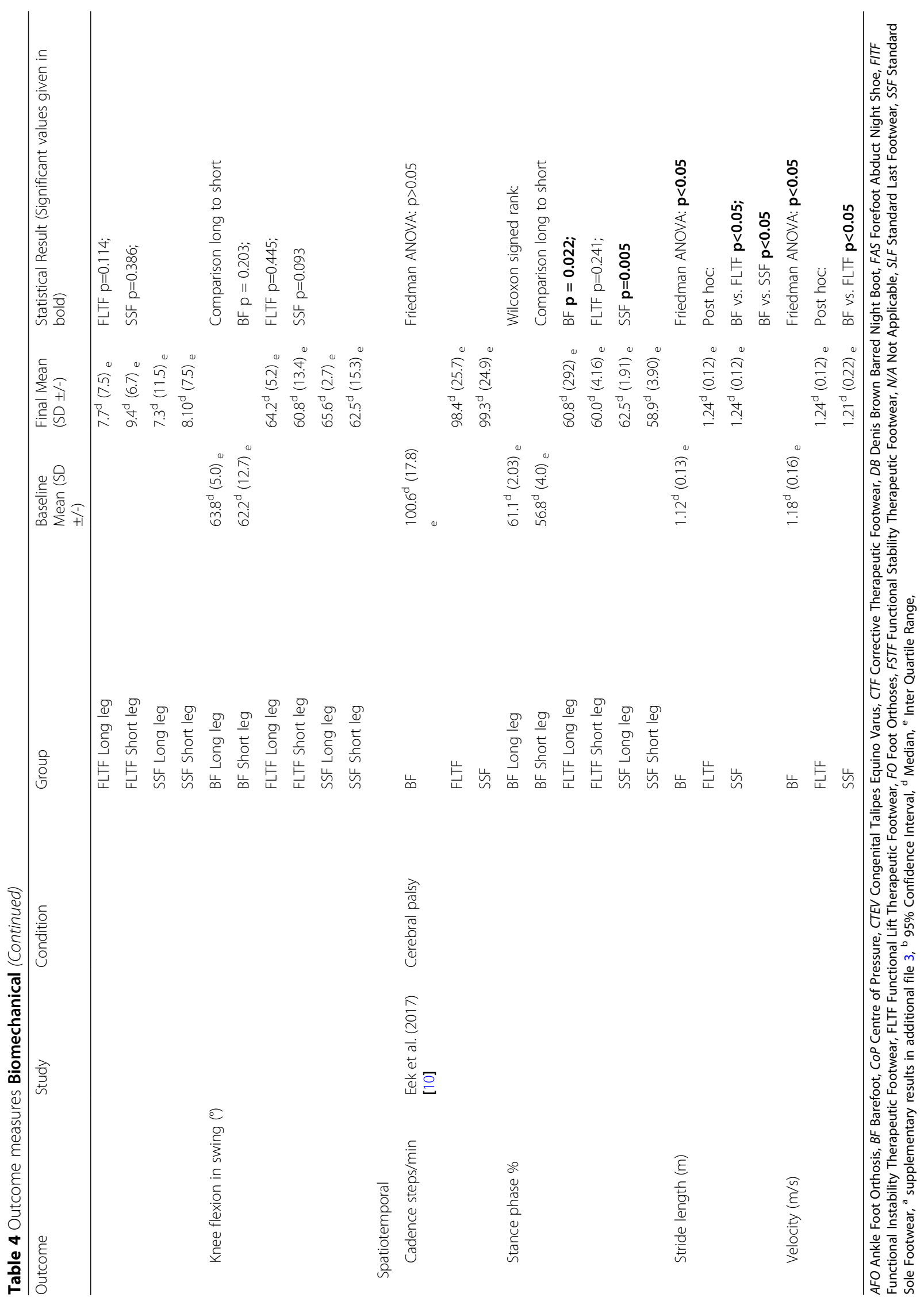


the functional footwear grouping studies [11, 46]. None of the studies blinded the participants to the intervention, with only one study blinding the assessor [14]. Sufficient information on the participant recruitment strategy was provided in only two studies [10,38]. Three of the studies stipulated a brief wearing in period to allow the child to become accustomed to walking in the interventions [10, 11, 14]. Functional footwear was split into three design characteristic subgroups: Stability, Instability, and Lift as defined by the previous scoping review [24].

Stability footwear There were seven studies in this subgrouping with various footwear designs used amongst the studies (Table 2). Five studies involved footwear offering some form of medial-lateral stability with arch inlay and/or reinforced heel counte $\mathrm{r}[11,14,38,39$, 41] and two studies involved footwear with anteriorposterior sole wedging that work alongside Ankle Foot Orthoses (AFO) to offer sagittal stability [40, 42]

In relation to footwear that offered mediolateral stability, the study designs consisted of four before-after studies (level III evidence) [11, 14, 39, 41] and one survey study (level IV evidence) [38]. Two of these studies were of fair QI [11, 14] and two poor QI [39, 41]. The survey study met $64 \%$ of the survey quality criteria [38]. The medical conditions of the participants were mobile pes planus, Down's syndrome, in-toeing and Duchenne muscular-dystrophy (Table 1) [11, 14, 38, 39, 41]. Various comparators were considered (Table 1). Barefoot conditions, walking or stance, was the baseline assessment in three of the five studies [11, 14, 39]. Standard unmodified footwear was considered in three of the studies [38, 39, 41]. Arch inlays/foot orthosis was a comparator either fitted to stability footwear in one paper [39] or to standard footwear in another paper [11]. AFOs, Knee Ankle Foot Orthoses (KAFO), and standing frames were additionally considered in one study [38]. Medical taping was a consideration in one study [14]. Stability footwear with various sole modifications were compared in one study [41].

Primary outcomes considered both biomechanical (Table 4) and skeletal geometric measures (Table 3). One study demonstrated statistically significant changes in spatiotemporal parameters (increase in velocity and stride length, reduction in the base of support) in children with Down's syndrome whilst wearing stability footwear compared to the barefoot condition [14]. However, no differences were noted between the stability footwear group and the taping comparator group in this study [14]. One study demonstrated a statistically significant reduction in the centre of pressure $(\mathrm{CoP})$ displacement and increased step velocity in the stability footwear compared to the barefoot condition for individuals with pes planus [20]. No statistically significant difference was found in step symmetry in this study between barefoot and stability footwear conditions. However, the regular shoe with orthosis demonstrated a statistically significant increase in step symmetry compared to stability footwear conditions [11]. Mediolateral wedged sole modifications were shown to have no statistically significant effect on intoed angle of gait. Torqheels (circular sole additions that impart a torque on ground contact [47]) did show a statistically significant reduction of the in-toed angle of gait (approximately 33\%) compared to a standard soled footwear [41]. Skeletal geometry outcomes used were immediate weight-bearing radiographic alignment changes to the medial longitudinal arch in participants with symptomatic pes planus. Skeletal alignment was seen to improve in stability footwear vs. barefoot conditions [39]. However, no statistical analysis was performed on these effects. Additionally, there was absent reporting of the changes to these angles in standard footwear conditions [39].

Secondary outcomes, as outlined by this review, were explored in two of the mediolateral stability footwear studies. Reduction of foot fatigue and pain in pes planus were investigated in one paper [39]. This paper demonstrated these outcomes improved for the stability footwear intervention compared to standard footwear and arch inlay. However, no statistical analysis was performed on these findings. The second paper considered surveying parents of children with Duchenne's muscular dystrophy (DMD) as to the reluctance to use the prescribed assistive device and pain whilst using the device [38] (Table 5). This demonstrated that stability footwear was associated with less reluctance to wear and less pain experienced compared to AFOs, KAFOs and standing frames. This study failed to provide information on the design or testing of the questionnaire. Additionally, there was no statistical analysis performed, and it was unclear as to the severity of the DMD amongst the different interventions or if the pain measured was from the device or from the condition itself.

In relation to footwear that offered sagittal stability, study design consisted of one before-after design [40] and one cross over study [42]; both studies were of fair QI. The medical conditions of the participants consisted of spastic cerebral palsy with knee hyperextension [40] or crouch gait [42] (Table 1). Comparators consisted of standard footwear in one study [42] and AFO worn with standard footwear combination in both studies [40, 42] (Table 1). Biomechanical outcomes were considered in both these studies [40, 42] (Table 4). One study demonstrated a statistically significant improvement on knee hyperextension and shank to vertical angle (SVA) kinematics in sagittal wedged soled footwear in combination with AFO compared to the standard sole footwear with AFO [40]. However, no kinetic or spatiotemporal variable reached statistical significance [40]. Standing 
Table 5 Secondary outcome measures

\begin{tabular}{|c|c|c|c|c|c|}
\hline Outcome & Study & Condition & Group & Baseline Mean (SD $\pm /-)$ & Final $^{\mathbf{a}}$ Mean $(\mathrm{SD}+/-)$ \\
\hline \multicolumn{6}{|c|}{ Functional Stability Therapeutic Footwear } \\
\hline Pain whilst using device & Bakker et al. (1997) [38] & DMD & FSTF & N/A & $1.42(0.53)$ \\
\hline \multirow[t]{2}{*}{$1=$ no pain } & & & Own footwear & N/A & $1.02(0.51)$ \\
\hline & & & KAFO & N/A & $3.0(1.87)$ \\
\hline \multirow[t]{2}{*}{$5=$ great deal of pain } & & & SF & N/A & $2.33(1.03)$ \\
\hline & & & AFO & N/A & $2.20(1.39)$ \\
\hline Reluctance to use device & & & FSTF & N/A & $2.28(1.25)$ \\
\hline \multirow[t]{2}{*}{$1=$ not reluctant } & & & Own footwear & N/A & $1.29(1.35)$ \\
\hline & & & KAFO & N/A & $3.0(1.58)$ \\
\hline \multirow[t]{2}{*}{$5=$ great deal of reluctance } & & & SF & N/A & $3.66(1.21)$ \\
\hline & & & AFO & N/A & $2.85(1.53)$ \\
\hline
\end{tabular}

AFO Ankle Foot Orthosis, DMD Duchenne Muscular Dystrophy, FSTF Functional Stability Therapeutic Footwear, KAFO Knee Ankle Foot Orthosis, N/A Not Applicable, SF Standing Frame, ${ }^{a}$ No statistical test for significance performed

balance was considered in the second study. This study found statistically significant improvement for differences in standing balance in a sub-set analysis of diplegic individuals with Gross Motor Function Scores (GMFS) 2-3 for AFOs and anteroposterior sagittal wedged footwear combination intervention compared to both standard footwear and AFO standard footwear combination [42].

Instability footwear This subgrouping consisted of one study that considered commercially available $\mathrm{MBT}^{\circ}$ footwear [43]. This footwear consists of a rounded sole shoe with a midfoot pivot [43] (Table 2). The study was a before-after design (level III evidence) of poor QI. The health conditions considered were highly varied in the group and consisted of cerebral palsy, Prader Willi, unspecified motor and development delay, Cornelia de Lange syndrome and Attention Deficit Hyperactive Disorder (ADHD) (Table 1). The grading and degree of the mobility impairments of the participants were not fully described. All individuals wore the MBT footwear for the 8-week period and were tested barefoot and in the MBT footwear (Table 1 and 4). Biomechanical outcomes of static and dynamic balance were considered in this study (Table 4). No spatiotemporal kinematic or kinetic outcomes were considered. This footwear did not demonstrate any statistically significant effects on static balance and a number of dynamic balance outcomes; these results are presented in Additional file 3. However, two of the dynamic balance outcomes were seen to statistically significantly improve, with a reduction in the number of falls seen over the course of the study and improvement in the mediolateral control of the centre of pressure displacement. It must be noted that two of the participants were unavailable for the four-week testing point and one other participant failed to understand the instructions for the control aspect of dynamic balance testing. Intention to treat analysis was not reported to account for this drop off in participation.

Lift footwear Lift footwear was described as consisting of unilateral outer-sole adhesions (Table 2) [10, 44]. This subgroup consisted of two before and after studies; one fair QI [10] and one poor QI [44]. Poor reporting of the intervention and the participants affected the QI of one study [44]. Conditions considered were limb length inequality in combination with either, idiopathic scoliosis [44] or spastic cerebral palsy [10] (Table 1). Barefoot conditions, walking or stance, was considered as a comparator in both studies [10, 44], with standard sole footwear also considered in one study [10] (Table 1). Spatiotemporal and kinematic variables were considered in individuals with spastic cerebral palsy and limb length inequality, in one of the studies [10] (Table 4). Statistically significant differences seen between stance time in the long and short leg in barefoot and unmodified shod conditions were not seen in the lifted footwear intervention. Velocity was also statistically significantly increased in the lifted footwear compared to the barefoot conditions. Statistically significant kinematic differences between hip flexion at initial contact and swing and ankle dorsiflexion in stance seen between the long and short limb in the barefoot condition were no longer significant in the lifted footwear condition. The second study considered skeletal geometric measures of acute changes on, lower limb, pelvic, and spinal posture through radiographs and 3D marker system of first barefoot, then lifted sole conditions [44] (Table 3). Sole lifted conditions statistically significantly reduced the Cobb angle, pelvic tilt, version between right and left iliac bones, and shoulder tilt compared to barefoot conditions. These 
findings are thought to demonstrate acute improvements in idiopathic scoliosis posture.

\section{Discussion}

The review identified 13 empirical studies that explored the effects of therapeutic footwear in children with mobility impairment. Study quality was negatively affected in most studies by the reporting strategy, with a lack of descriptions of basic participant anthropometrics and inadequate blinding of participants and assessors impacting on generalisability and internal and external validity. Another consideration that may impact on long term conservative footwear management is compliance with the intervention [48]; this was not accounted for or was inconsistently measured in the studies potentially introducing confounding bias $[49,50]$.

The medical conditions with the highest number of studies were pes planus (five studies) and cerebral palsy (four studies). It must be noted three studies, considering pes planus appeared to only acknowledge the postural presentation with no apparent symptoms or other underlying pathology identified [11, 12, 37]. Therapeutic interventional studies should consider expanding on the descriptors of inclusion for pes planus in children [5153] to avoid the possibility of medicalising healthy physiological development [54] and potential detriment to the health economy and the individual $[55,56]$. The effects of footwear as a therapeutic intervention on other noteworthy conditions that impact on children's mobility such as joint hypermobility syndrome [57], spina bifida [58], developmental coordination disorder [59], juvenile idiopathic arthritis [60], and Charcot Marie Tooth [61] were not considered in the included studies.

The age of the participants showed distinct differences between the two main footwear groupings with corrective footwear considering a younger age range (11 months to 5 years) and functional footwear a broader age range (3 to 15 years) (Additional file 2). This may be explained by the increased percentage of cartilage in the infant skeleton having the perceived potential to be influenced by conservative intervention $[62,63]$ in relation to corrective footwear, and the broader age range in functional footwear linked to the ongoing need for assistive aid for children with mobility issues in daily activity. Primary outcomes were focused towards skeletal geometry in all of the corrective footwear studies as would be expected since the aim of treatment is to bring about realignment of the skeletal system in the lower limb [24]. Primary outcomes for functional footwear were focused on biomechanical variables in 7 out of the 10 studies. This again would be expected since the purpose of functional footwear is to assist children's gait parameters [24].
In consideration of corrective footwear grouping, the studies explored their effects for asymptomatic flexible pes planus and CTEV alongside nocturnal barred footwear post serial casting. One fair quality study, for a relatively large sample size, would suggest that corrective footwear offers no effect on mobile asymptomatic pes planus in children [37]. One fair quality controlled group study [16] suggests daily use of corrective footwear alongside nocturnal splinted footwear can improve the equinus and varus positioning of the forefoot. However, caution must be observed as CTEV is a heterogeneous pathology [64], and this study failed to report the aetiologies of the participants' deformities, thus affecting the generalisability of the study's findings.

The studies across the subgroupings of functional footwear were mainly experimental before and after design and one survey (Additional file 4 and 5 ). The significance of the changes observed in these studies could have been a short term effect [65] due to an insufficient wearing in and accommodation period. A learning effect could also impact on the findings [66] with participants able to anticipate factors such as those that required dynamic balance [43]. Further research with suitable wearing in periods and a control group study design would be beneficial to corroborate the findings of these studies. Stability footwear was seen to comprise of two general designs; one to assist mediolateral stability $[11,14]$ and one to work alongside AFOs to assist sagittal stability $[40,42]$. For mediolateral stability design, one fair quality study demonstrated statistically significant effects on velocity and mediolateral CoP displacement in children with pes planus between stability footwear intervention and barefoot [11] with one further fair quality study demonstrating statistically significant effects on velocity, stride length, and base of support for stability footwear vs. barefoot conditions in individuals with Down's syndrome [14]. However, both the studies did not compare these effects with a standard children's footwear condition that has also demonstrated statistically significant effects on spatiotemporal measures in children compared to barefoot conditions [18]. This opens the significance of the spatiotemporal findings for this footwear to debate and precludes any recommendations advocating this intervention over standard footwear in clinical practice for children with flexible pes planus or Downs syndrome. There is poor quality evidence that sole modification reduces the in-toed angle of gait by a third compared to standard sole footwear; however, the need to treat this developmental variant conservatively is debatable [67]. One survey indicated that stability footwear was associated with less reluctance to use and less pain than other assistive devices in individuals with DMD. However, the severity of the condition amongst those using the various devices was not stated; this precluded 
any informed clinical recommendation for the use of stability footwear in this condition. Those studies that considered sagittal stability demonstrated fair quality evidence in two studies that this footwear combined with a customised AFO can improve, knee and shank vertical angle in spastic $\mathrm{CP}$ [40] or standing balance in spastic diplegic GMFS 2-3 crouch gait [42]. Therefore sagittal stability footwear could tentatively be recommended over standard retail footwear for AFO footwear combination in children with spastic CP. Evidence indicated that instability footwear improves dynamic balance (number of falls and control of mediolateral CoP displacement) in a range of children's developmental disabilities. However, the quality of this study was poor, with failure to account for dropout across the testing period, and a diverse range of mobility impairments considered in the sample (Table 1) questioning the validity of the central trend analysis obtained [43].

Lift footwear offered fair quality evidence in one study to improve the symmetry of a wide range of kinematic and spatiotemporal gait parameters between the long and short limb in individuals with spastic cerebral palsy potentially supporting its use for individuals with this clinical presentation [10]. Spinal and pelvic skeletal geometry were seen to improve in individuals with idiopathic scoliosis; however, this was of poor quality with no standard footwear comparator and insufficient information provided on the participants and recruitment strategy opening the significance and generalisability of the findings to debate [44].

It was noted that a number of studies amongst the functional footwear grouping contained a degree of heterogeneity in the participant's age ranges and variable motor impairment. There were over seven year age ranges in some studies [40, 42, 43]; since development affects biomechanical parameters $[18,68]$, this should be considered when averaging biomechanical outcome data. Further consideration should be given to the studies that averaged biomechanical outcome data amongst individuals with cerebral palsy [10, 40, 42] as this condition has a significant range of motor impairment that may not be amenable to central trend analysis [69-72].

There is relatively limited research concerning any grouping of therapeutic footwear. Level of evidence ranged from II to IV, but no study exceeded a quality assessment of fair, due to methodology that affected both internal and external validity. This entails a conservative recommendation from the current evidence base concerning clinical usage of therapeutic footwear. There appears to be evidence that corrective footwear is not recommended as an intervention for developmental pes planus since there is no apparent favourable outcome compared to standard footwear in infants and young children. With an unnecessary prescription of corrective footwear leading to potential over-medicalisation of typical development and psychosocial detriment in early adult life [54, 56]. Functional footwear appears to be able to play a role in assisting children with mobility impairment across a broader age range than corrective footwear; however, these studies invariably suffer from a small sample size potentially being underpowered to detect any statistically significant effect. Future studies for functional therapeutic footwear must consider a comparison with standard footwear, as suggested by Wegener et al. [18], to factor in the effects of regular footwear on children's gait in comparison to barefoot conditions. Further comparison to other assistive devices such as foot orthoses is warranted in order to inform when stability footwear should be used as an alternative or in combination with foot orthoses, and where lift therapy for limb length inequality is best addressed with removable inlays or external shoe modifications.

Other recommendations for general therapeutic footwear research include clear reporting of participant characteristics and the distribution of demographics between treatment groups, to include, sex, height and mass which have demonstrated effects on foot function and skeletal geometry in previous studies [73-75]. Consideration of participant recruitment strategies is required; being mindful of institutional bias in the samples selected, and more transparent recruitment reporting to inform on the external validity of the work [33]. The lack of consideration of adverse events across the studies warrants comment since it is imperative intervention studies declare adverse events or the measures taken to capture these, as appropriate evidence base should identify the potential harms as well as benefits of any therapeutic intervention [76].

The psychosocial impact of therapeutic intervention is an important consideration for mobility-impaired children [77]. The World Health Organisation's international classification of function for children living with disabilities considers a number of factors to ensure the child can achieve the highest quality of life [2]. The current evidence base concerning therapeutic footwear has chiefly focused on the body structure and functional aspects of the ICF-CY but has not attempted to assess the long-term or psychosocial effects the intervention may have on the child's quality of life in terms of the ability to participate in daily activities or relief of pain.

\section{Limitations of the current study}

The initial screening of the studies that identified children's therapeutic footwear was performed independently by the one author $(\mathrm{MH})$ during the preceding scoping review [24], which may have opened 
these processes to personal bias. The review has considered only those articles with an available English language abstract which may have impacted on the scope of research. Incomplete description of the therapeutic footwear together with the lack of information on basic anthropometrics (height, mass, BMI), heterogeneity of the participants, and the broad range of outcomes precluded a quantitative analysis of the aggregated results which could be perceived as a limitation. There were 76 different outcome measures considered across the included studies with few reporting on the same outcome measures. The definition and adoption by researchers to minimum sets of condition-specific outcome measures, such as those presented by the International Consortium for Health Outcome Measurement (ICHOM) [78], will enable between study comparisons and meta-analyses of future research.

\section{Conclusion}

There are a limited number of studies exploring the effects of children's therapeutic footwear; these have mainly been studied on children with pes planus and cerebral palsy. Limited fair quality level II evidence is available that corrective footwear has no statistically significant effect on apparent typical developmental pes planus. Conversely, there is limited fair quality level II evidence that it can offer a corrective effect in mild to moderate cases of CTEV in infancy. Functional therapeutic footwear offers limited fair quality level III evidence on apparent improvement to gait parameters in pre-school and primary school-aged children with pes planus, Down's syndrome or CP. Included studies explored body structure and functional aspects of the WHO ICF-CY (biomechanical and skeletal geometry outcomes). However, psychosocial aspects of the ICF-CY concerning the quality of life appears largely absent in the research.

Review findings suggest that further research on therapeutic footwear with robust study designs is warranted. The outcome measures should consider a full range of ICF-CY aspects, and the reporting should include a clear description of the footwear interventions, participant characteristics, recruitment strategy and measures of adverse events. These recommendations will improve the current evidence base for therapeutic footwear as an intervention for children with mobility impairment.

\section{Supplementary information}

Supplementary information accompanies this paper at https://doi.org/10. 1186/s13047-020-00390-3.

Additional file 1. Example of Medline (EBSCO) search strategy
Additional file 2. Age ranges for children with mobility impairment in the included studies.

Additional file 3. Supplementary biomechanical outcome results Additional file 4. Evidence level and quality assessment of experimental studies

Additional file 5. Level of evidence and quality assessment of survey study.

Additional file 6. PRISMA 2009 Checklist.

\section{Abbreviations}

AFO: Ankle foot orthoses; CoP: Centre of pressure; CTEV: Congenital talipes equino varus; DMD: Duchenne's muscular dystrophy; GMFS: Gross Motor Function Scores; KAFO: Knee Ankle Foot Orthoses; OCEBM: Oxford Centre for Evidence-Based Medicine; QI: Quality assessment index; RCTs: Randomised control trials; WHO ICF-CY: World Health Organisation's international classification of function child and youth version

\section{Acknowledgments}

Not applicable

\section{Authors' Contributions}

$\mathrm{MH}, \mathrm{AH}$ and $\mathrm{NC}$ conceived the idea and study design of the review. $\mathrm{MH}$ carried out the literature search. Inclusion and exclusion of full text articles was reached by consensus by $\mathrm{MH}, \mathrm{AH}$ and $\mathrm{NC}$. Data was extracted by $\mathrm{MH}$ and $\mathrm{AH}$ consensus of the extracted data was reached with $\mathrm{MH}$ and $\mathrm{AH}$. All the authors have made a significant contribution to drafting the manuscript and have seen and approved the final manuscript.

\section{Funding}

This work was supported by a PhD bursary provided by Staffordshire University.

\section{Availability of data and materials}

All data generated or analysed during this study are included in this published article [and its additional files].

Ethics approval and consent to participate

Not applicable

\section{Consent for publication}

Not applicable

\section{Competing interests}

The authors declare that they have no competing interests

Received: 24 December 2019 Accepted: 30 April 2020

Published online: 13 May 2020

\section{References}

1. Blackburn CM, Spencer NJ, Read JM. Prevalence of childhood disability and the characteristics and circumstances of disabled children in the UK: secondary analysis of the Family Resources Survey. BMC Pediatr. 2010;10:21.

2. World Health Organization. International Classification of Functioning, Disability and Health Children \& Youth Version, http://apps.who.int/iris/ bitstream/handle/10665/43737/? sequence $=1$ (2007, accessed 15 Oct 2018).

3. contact.org.uk. The next chapter in our story, https://contact.org.uk/media/ 841575/our_strategy_2015-2020_lores.pdf (accessed 5 June 2019).

4. DWP. Family Resources Survey 2015/16, https://www.gov.uk/government/ statistics/family-resources-survey-financial-year-201516 (2016, accessed 5 June 2019).

5. UNICEF. THE STATE OF THE WORLD'S CHILDREN 2013. United Nations Publication, https://data.unicef.org/wp-content/uploads/2015/12/SOWC 2 013_75.pdf (2013, accessed 14 May 2018).

6. Ivanyi B, Schoenmakers M, Van Veen N, Maathuis K, Nollet F, Nederhand M. The effects of orthoses, footwear, and walking aids on the walking ability of children and adolescents with spina bifida: A systematic review using International Classification of Functioning, Disability and Health for Children and Youth (ICF-CY) as a ref. Prosthet Orthot Int. 2015;39:437-43. 
7. Bartkowlak Z, Łuczak-Piechowiak A, Zgorzalewicz-Stachowiak M, et al. Orthopedic equipment applied in children with cerebral palsy. Fizjoterapia / Physiother. 2008;16:99-113.

8. Staheli LT, Giffin L. Corrective shoes for children: a survey of current practice. Pediatrics. 1980;65:13-7.

9. Staheli LT. Corrective shoes for children: are they really necessary? J Musculoskelet Med. 1996;13:11-5.

10. Eek MN, Zügner R, Stefansdottir I, Tranberg R. Kinematic gait pattern in children with cerebral palsy and leg length discrepancy: Effects of an extra sole. Gait Posture. 2017;55:150-6.

11. Aboutorabi A, Saeedi H, Kamali M, Farahmand B, Eshraghi A, Dolagh RS. Immediate effect of orthopedic shoe and functional foot orthosis on center of pressure displacement and gait parameters in juvenile flexible flat foot. Prosthet Orthot Int. 2014;38:218-23

12. Kanatlı U, Aktas $\mathrm{E}$, Yetkin $\mathrm{H}$, et al. Do corrective shoes improve the development of the medial longitudinal arch in children with flexible flat feet? J Orthop Sci. 2016;21:662-6.

13. Holt KS. Mobility aids and appliances for disabled children. BMJ. 1991;302: 105-7.

14. Abd Elkader SM, Abd Elhafz YN, Al-Abdulrazaq SS. Foot taping versus medical shoes on kinematic gait parameters in children with down's syndrome. World Appl Sci J. 2013;27:311-7.

15. Williams CM, Pacey V, de Bakker PB, Caserta AJ, Gray K, Engelbert RH. Interventions for idiopathic toe walking. Cochrane Database Syst Rev; 2016. Epub ahead of print 3 October 2016. DOl: https://doi.org/10.1002/14651858. CD012363.

16. Chen W, Pu F, Yang Y, et al. Correcting Congenital Talipes Equinovarus in Children Using Three Different Corrective Methods: A Consort Study. Med (United States). 2015;94:e1004.

17. Nester CJ, Graham A, Martinez-Santos A, et al. National profile of foot orthotic provision in the United Kingdom, part 2: podiatrist, orthotist and physiotherapy practices. J Foot Ankle Res. 2018;11:10.

18. Wegener C, Hunt AE, Vanwanseele B, Burns J, Smith RM. Effect of children's shoes on gait: a systematic review and meta-analysis. J Foot Ankle Res. 2011:4:3.

19. Wolf S, Simon J, Patikas D, et al. Foot motion in children shoes: a comparison of barefoot walking with shod walking in conventional and flexible shoes. Gait Posture. 2008:27:51-9.

20. Aboutorabi A, Arazpour M, Ahmadi Bani M, Saeedi H, Head JS. Efficacy of ankle foot orthoses types on walking in children with cerebral palsy: A systematic review. Ann Phys Rehabil Med. 2017;60:393-402.

21. Eddison N, Chockalingam N. The effect of tuning ankle foot orthosesfootwear combination on the gait parameters of children with cerebral palsy. Prosthet Orthot Int. 2013;37:95-107.

22. Lintanf M, Bourseul J-S, Houx L, Lempereur M, Brochard S, Pons C. Effect of ankle-foot orthoses on gait, balance and gross motor function in children with cerebral palsy: a systematic review and meta-analysis. Clin Rehabil. 2018;32:1175-88.

23. Betancourt JP, Eleeh P, Stark S, Jain NB. Impact of Ankle-Foot Orthosis on Gait efficiency in Ambulatory Children with Cerebral Palsy. Am J Phys Med Rehabil. 2019;1.

24. Hill M, Healy A, Chockalingam N. Key concepts in children's footwear research: a scoping review focusing on therapeutic footwear. J Foot Ankle Res. 2019;12:25.

25. Morrison SC, Price C, McClymont J, Nester C. Big issues for small feet: developmental, biomechanical and clinical narratives on children's footwear. J Foot Ankle Res. 2018;11:39.

26. Davies N, Branthwaite $H$, Chockalingam N. Where should a school shoe provide flexibility and support for the asymptomatic 6- to 10-year-olds and on what information is this based? A Delphi yielded consensus. Prosthet Orthot Int. 2015;39:213-8.

27. Moher D, Liberati A, Tetzlaff J, Altman DG. Preferred Reporting Items for Systematic Reviews and Meta-Analyses: The PRISMA Statement. PLoS Med 2009:6:e1000097.

28. Farid-Kapadia M, Askie L, Hartling L, et al. Do systematic reviews on pediatric topics need special methodological considerations? 2017; 17: 57.

29. Kapadia MZ, Askie L, Hartling L, et al. PRISMA-Children (C) and PRISMAProtocol for Children (P-C) Extensions: a study protocol for the development of guidelines for the conduct and reporting of systematic reviews and meta-analyses of newborn and child health research. BMJ Open. 2016;6:e010270
30. Hill M, Healy A, Chockalingam N. Effectiveness of therapeutic footwear for children: a systematic review (review protocol). PROSPERO International prospective register of systematic reviews:, https://www.crd.york.ac.uk/ PROSPERO/display_record.php? RecordID=97038 (accessed 7 June 2019).

31. Munn Z, Tufanaru C, Aromataris E. JBI's Systematic Reviews: data extraction and synthesis. AJN, Am J Nurs. 2014;114:49-54.

32. OCEBM Levels of Evidence Working Group. The Oxford Levels of Evidence 2 Oxford Centre for Evidence-Based Medicine., https://www.cebm.net/2016/ 05/ocebm-levels-of-evidence/ (accessed 6 Oct 2019).

33. Downs SH, Black N. The feasibility of creating a checklist for the assessment of the methodological quality both of randomised and non-randomised studies of health care interventions. J Epidemiol Community Health. 1998; 52:377-84.

34. Trac MH, McArthur $E$, Jandoc $R$, et al. Macrolide antibiotics and the risk of ventricular arrhythmia in older adults. CMAJ. 2016;188:E120-9.

35. Mackenzie A, Rome K, Evans AM. The efficacy of nonsurgical interventions for pediatric flexible flat foot: A critical review. J Pediatr Orthop. 2012;32: 830-4.

36. Burns KEA, Kho ME. How to assess a survey report: a guide for readers and peer reviewers. C Can Med Assoc J. 2015;187:E198.

37. Wenger DR, Mauldin D, Speck G, Morgan D, Lieber RL. Corrective Shoes and Inserts as Treatment for Flexible Flatfoot in Infants and Children. J Bone Jt Surg Am. 1989;71:953-4.

38. Bakker JPJ, De Groot IJM, De Jong BA, Van Tol-De Jager MA, Lankhorst GJ. Prescription pattern for orthoses in The Netherlands: use and experience in the ambulatory phase of Duchenne muscular dystrophy. Disabil Rehabil. 1997;19:318-25.

39. Basta NW, Mital MA, Bonadio O, Johnson A, Kang SY, O'Connor J. A comparative study of the role of shoes, arch supports, and navicular cookies in the management of symptomatic mobile flat feet in children. Int Orthop. 1977;1:143-8.

40. Jagadamma KC, Coutts FJ, Mercer TH, et al. Effects of tuning of ankle foot orthoses-footwear combination using wedges on stance phase knee hyperextension in children with cerebral palsy - preliminary results. Disabil Rehabil Assist Technol. 2009;4:406-13.

41. Knittel G, Staheli LT. The effectiveness of shoe modifications for intoeing. Orthop Clin North Am. 1976;7:1019-25.

42. Wesdock KA, Edge AM. Effects of wedged shoes and ankle-foot orthoses on standing balance and knee extension in children with cerebral palsy who crouch. Pediatr Phys Ther. 2003;15:221-31.

43. Ramstrand N, Andersson CB, Rusaw D, Björk Andersson C, Rusaw D. Effects of an unstable shoe construction on standing balance in children with developmental disabilities: a pilot study. Prosthet Orthot Int. 2008;32:422-33.

44. Zabjek KF, Leroux MA, Coillard C, et al. Acute postural adaptations induced by a shoe lift in idiopathic scoliosis patients. Eur Spine J Off Publ Eur Spine Soc Eur Spinal Deform Soc Eur Sect Cerv Spine Res Soc. 2001;10:107-13.

45. Cunningham JB, McCrum-Gardner E. Power, effect and sample size using GPower: Practical issues for researchers and members of research ethics committees. Evid Based Midwifery. 2007:5:132-6.

46. Raczkowski JW, Daniszewska B, Zolynski K. Functional scoliosis caused by leg length discrepancy. Arch Med Sci. 2010;6:393-8.

47. Rodenberger CA. Torqheels. In: Orthopaedic Mechanics. Elsevier, 1981, pp. 175-198.

48. Sangiorgio SN, Ho NC, Morgan RD, Ebramzadeh E, Zionts LE. The Objective Measurement of Brace-Use Adherence in the Treatment of Idiopathic Clubfoot. J Bone Jt Surg - Am Vol. 2016;98:1598-605.

49. Spencer EA HC. Compliance bias. Catalogue Of Biases 2018, https:// catalogofbias.org/biases/compliance-bias/ (accessed 25 Feb 2020).

50. Nielsen RO, Bertelsen ML, Ramskov D, et al. Randomised controlled trials (RCTs) in sports injury research: authors-please report the compliance with the intervention. Br J Sports Med. 2020;54:51-7.

51. Banwell HA, Paris ME, Mackintosh S, Williams CM. Paediatric flexible flat foot: how are we measuring it and are we getting it right? A systematic review. J Foot Ankle Res. 2018;11:21.

52. Uden $H$, Scharfbillig $R$, Causby $R$. The typically developing paediatric foot: how flat should it be? A systematic review. J Foot Ankle Res. 2017;10:37.

53. Dars S, Uden H, Kumar S, Banwell HA. When, why and how foot orthoses (FOs) should be prescribed for children with flexible pes planus: a Delphi survey of podiatrists. PeerJ. 2018;6:e4667.

54. Kaczmarek E. How to distinguish medicalization from over-medicalization? Med Heal Care Philos. 2019;22:119-28. 
55. Carli A, Saran N, Kruijt J, Alam N, Hamdy R. Physiological referrals for paediatric musculoskeletal complaints: A costly problem that needs to be addressed. Paediatr Child Health. 2012;17:e93-7.

56. Driano AN, Staheli LT, Staheli LT. Psychosocial development and corrective shoewear use in childhood. J Pediatr Orthop. 1998;18:346-9.

57. Scheper MC, Nicholson LL, Adams RD, Tofts L, Pacey V. The natural history of children with joint hypermobility syndrome and Ehlers-Danlos hypermobility type: a longitudinal cohort study. Rheumatology. 2017;56: 2073-83.

58. Schoenmakers MAGC, Uiterwaal CSPM, Gulmans VAM, Gooskens RHJM, Helders PJM. Determinants of functional independence and quality of life in children with spina bifida. Clin Rehabil. 2005;19:677-85.

59. Wilson PH, Ruddock S, Smits-Engelsman B, Polatajko H, Blank R. Understanding performance deficits in developmental coordination disorder: a meta-analysis of recent research. Dev Med Child Neurol. 2013;55: 217-28.

60. Hendry G, Gardner-Medwin J, Watt GF, Woodburn J. A survey of foot problems in juvenile idiopathic arthritis. Musculoskeletal Care. 2008;6:221-32.

61. Kennedy RA, Carroll K, McGinley JL. Gait in children and adolescents with Charcot-Marie-Tooth disease: a systematic review. J Peripher Nerv Syst. 2016; 21:317-28.

62. Brewster MBS, Gupta M, Pattison GTR. Dunn-van der Ploeg ID. Ponseti casting: a new soft option. J Bone Jt Surgery. Br Vol. 2008;90:1512-5.

63. Williams CM, James AM, Tran T. Metatarsus adductus: development of a non-surgical treatment pathway. J Paediatr Child Heal. 2013;49:E428-33.

64. David MG. Simultaneous correction of congenital vertical talus and talipes equinovarus using the ponseti method. J Foot Ankle Surg. 2011;50:494-7.

65. MacLean CL, Davis IS, Hamill J. Short- and long-term influences of a custom foot orthotic intervention on lower extremity dynamics. Clin J Sport Med. 2008:18:338-43.

66. Wu G, Sanderson B, Bittner V. The 6-minute walk test: How important is the learning effect? Am Heart J. 2003;146:129-33.

67. Uden H, Kumar S. Non-surgical management of a pediatric 'intoed'gait pattern - a systematic review of the current best evidence. J Multidiscip Healthc. 2012;5:27-35.

68. McKay MJ, Baldwin JN, Ferreira P, et al. Spatiotemporal and plantar pressure patterns of 1000 healthy individuals aged 3-101 years. Gait Posture. 2017;58: 78-87.

69. Tugui RD, Antonescu D. Cerebral palsy gait, clinical importance. Maedica (Buchar). 2013;8:388-93.

70. Kim Y, Bulea TC, Damiano DL. Children With Cerebral Palsy Have Greater Stride-to-Stride Variability of Muscle Synergies During Gait Than Typically Developing Children: Implications for Motor Control Complexity. Neurorehabil Neural Repair. 2018;32:834-44

71. Domagalska-Szopa M, Szopa A. Gait pattern differences between children with mild scoliosis and children with unilateral cerebral palsy. PLoS One; 9 . Epub ahead of print 4 August 2014. https://doi.org/10.1371/journal.pone.01 03095.

72. Domagalska Szopa M, Szopa A. Gait Pattern Differences Among Children With Bilateral Cerebral Palsy. Front Neurol; 10. Epub ahead of print 12 March 2019. DOI: https://doi.org/10.3389/fneur.2019.00183.

73. Jiménez-Ormeño E, Aguado X, Delgado-Abellán L, et al. Foot morphology in normal-weight, overweight, and obese schoolchildren. Eur J Pediatr. 2013;172:645-52.

74. Morrison SC, McCarthy D, Mahaffey R. Associations Between Obesity and Pediatric Foot Dimensions. J Am Podiatr Med Assoc. 2018;108:383-9.

75. Barisch-Fritz B, Schmeltzpfenning T, Plank C, Hein T, Grau S. The effects of gender, age, and body mass on dynamic foot shape and foot deformation in children and adolescents. Footwear Sci. 2014;6:27-39.

76. Ioannidis JPA. Adverse Events in Randomized Trials. Arch Intern Med. 2009; 169:1737.

77. Guerette P, Furumasu J, Tefft D. The positive effects of early powered mobility on children's psychosocial and play skills. Assist Technol. 2013;25: 39-48.

78. ICHOM | Overall Pediatric Health Standard Set | Measuring Outcomes, https://www.ichom.org/portfolio/overall-pediatric-health/ . Accessed 14 Apr 2020

\section{Publisher's Note}

Springer Nature remains neutral with regard to jurisdictional claims in published maps and institutional affiliations.

\section{Ready to submit your research? Choose BMC and benefit from:}

- fast, convenient online submission

- thorough peer review by experienced researchers in your field

- rapid publication on acceptance

- support for research data, including large and complex data types

- gold Open Access which fosters wider collaboration and increased citations

- maximum visibility for your research: over $100 \mathrm{M}$ website views per year

At $\mathrm{BMC}$, research is always in progress.

Learn more biomedcentral.com/submissions 